\title{
Imaging normal pressure hydrocephalus: theories, techniques, and challenges
}

\author{
Nicole C. H. Keong, MD, FRCS, ${ }^{1,2}$ Alonso Pena, PhD, ${ }^{3}$ Stephen J. Price, PhD, FRCS, ${ }^{2}$ \\ Marek Czosnyka, PhD, ${ }^{2}$ Zofia Czosnyka, PhD, ${ }^{2}$ and John D. Pickard, FMedSci ${ }^{2}$
}

\begin{abstract}
${ }^{1}$ Department of Neurosurgery, National Neuroscience Institute and Duke-NUS Medical School, Singapore; ${ }^{2}$ Neurosurgical Division, Department of Clinical Neurosciences, University of Cambridge, United Kingdom; and ${ }^{3}$ SDA Bocconi School of Management, Milan, Italy
\end{abstract}

\begin{abstract}
The pathophysiology of NPH continues to provoke debate. Although guidelines and best-practice recommendations are well established, there remains a lack of consensus about the role of individual imaging modalities in characterizing specific features of the condition and predicting the success of CSF shunting. Variability of clinical presentation and imperfect responsiveness to shunting are obstacles to the application of novel imaging techniques. Few studies have sought to interpret imaging findings in the context of theories of NPH pathogenesis. In this paper, the authors discuss the major streams of thought for the evolution of NPH and the relevance of key imaging studies contributing to the understanding of the pathophysiology of this complex condition.
\end{abstract}

http://thejns.org/doi/abs/10.3171/2016.7.FOCUS16194

KEY WORDS NPH; theories; DTI; imaging

$\mathrm{N}$ ORMAL pressure hydrocephalus (NPH) was first described by Hakim and Adams in $1965^{29}$ as a syndrome of gait apraxia, dementia, and incontinence associated with normal CSF pressures and dilated ventricles. This condition predominantly affects the elderly, and these patients may display a combination of NPH and Alzheimer's or small-vessel disease. The diagnostic challenge in the management of each case is to balance the risks involved with surgery in this age group against the potential benefits of treating the component that may be remedied by CSF diversion. Neuropsychological profiling and CSF infusion studies can help predict which patients may benefit from CSF diversion; however, the resistance to CSF absorption is usually but not always increased in shunt-responsive NPH.

In 2005, the NPH guidelines study group concluded that a single standard for the prognostic evaluation of idiopathic NPH (iNPH) was lacking. ${ }^{50,65}$ The rigorous literature search performed by this group found that published results from supplementary tests varied greatly between centers. Determination of CSF outflow resistance via an infusion test was found to carry a sensitivity of $57 \%-100 \%$ and a positive predictive value of $75 \%-92 \%$, whereas prolonged external lumbar drainage in excess of $300 \mathrm{ml}$ was associated with a sensitivity of 50\%-100\% and a positive predictive value of $80 \%-100 \% .^{50}$ Therefore, imaging techniques are

ABBREVIATIONS CBF = cerebral blood flow; DESH = disproportionately enlarged subarachnoid-space hydrocephalus; $\mathrm{DTI}=$ diffusion tensor imaging; ICP = intracranial pressure; iNPH = idiopathic NPH; NPH = normal pressure hydrocephalus; $\mathrm{PET}=$ positron emission tomography; $\left.{ }^{11} \mathrm{C}\right] \mathrm{PiB}=$ carbon 11 -labeled Pittsburgh Compound B; rCBV = regional cerebral blood volume; Rcsf = resistance to CSF outflow; REM = rapid eye movement; ROI = region of interest; SINPHONI = Study of Idiopathic Normal Pressure Hydrocephalus on Neurological Improvement; SPECT = single photon emission computed tomography; VP = ventriculoperitoneal.

SUBMITTED May 1,2016. ACCEPTED July 8, 2016.

INCLUDE WHEN CITING DOI: 10.3171/2016.7.FOCUS16194. 
increasingly being developed as supplementary diagnostic tests and potential prognostic tools. There is limited Class I evidence that impaired cerebral blood flow (CBF) reactivity to acetazolamide is a predictor of successful CSF shunting, but single photon emission computed tomography (SPECT) is not a practical screening tool for NPH. Although attempts at predictive methodology, such as highvelocity aqueductal flow rate measurement on MRI, have achieved widespread acceptance in clinical practice, there is no Class I evidence (only 1 Class II study and 2 Class III studies) available to support this. ${ }^{31}$ An MRI-based diagnostic scheme used in a multicenter prospective study (Study of Idiopathic Normal Pressure Hydrocephalus on Neurological Improvement [SINPHONI] ${ }^{32}$ appears to suggest that features of disproportionately enlarged subarachnoid-space hydrocephalus (DESH) are meaningful in the evaluation of NPH.

Although the exact pathogenesis of NPH is unknown, many possible causes have been postulated, including cerebrovascular ischemia. Studies have demonstrated that periventricular blood flow and cerebrovascular autoregulation are reduced. ${ }^{55,58}$ It is also thought that biomechanical changes, such as the combination of tissue distortion caused by ventricular dilation, CSF and interstitial fluid stasis, and impaired autoregulation may result in failure of drainage of neurotoxic compounds such as amyloid- $\beta .{ }^{55,62,71}$ Increased CSF stroke volume through the aqueduct has also been demonstrated in the NPH population ${ }^{68}$ despite normal CSF pressures. The reaction of the cerebral mantle to all or some of these processes is poorly understood. It is thought that white matter tract connections serving the cortex could be disrupted in a variety of ways, including disconnection, swelling, stretching, and compression. Therefore, it is possible that some types of disruption may be more tolerable (i.e., more reversible) than others.

The development of novel neuroimaging tools and techniques has led to greater access to the visualization of physiological processes and structural detail. Many studies have focused on the refinement of such techniques for development as potential biomarkers for prognosis. Nevertheless, as the underlying pathophysiology of NPH remains unresolved, important questions also remain regarding the evolution of NPH. Only a few studies have seized the opportunity to reevaluate the theories of pathogenesis of $\mathrm{NPH}$ using developments in imaging techniques. In this review, we discuss imaging studies representing the major theory streams for the evolution of NPH. Key findings are summarized in Table 1.

\section{Theories of Pathogenesis}

Many theories have been advanced to explain the mechanisms underlying the development of the NPH syndrome (Fig. 1). However, the basic pathophysiological processes still remain unclear. Clearly, NPH may be a form of CSF circulation disorder, but progressive ventriculomegaly may not be the only active process in this condition. ${ }^{63}$ The inability to clear potentially toxic metabolites, such as amyloid- $\beta$ peptides and tau protein, could result in increased concentrations in brain fluid, leading to neuronal damage or dysfunction. ${ }^{70}$ The presence of $\mathrm{B}$ waves, abnormal
CSF pressure spikes, may result in intermittently raised intracranial pressures (ICPs), particularly during rapid eye movement (REM) sleep. The presence of these waves and the change in properties of aging brain parenchyma may make the older age group susceptible to progressive ventricular enlargement. ${ }^{20}$ The major theory streams proposed for the pathogenesis of NPH can be divided into 1) structural, 2) CBF, and 3) CSF flow subgroups. The components of each theory stream are expanded below prior to the discussion of the studies relevant to each.

\section{Structural}

\section{Tissue Distortion and Biomechanics}

Hakim and other authors have hypothesized that the starting point in the pathophysiology of NPH is tissue distortion secondary to raised intraventricular pressure. Initially, the pressure is highest in the periventricular area; the farther away from the ventricles the pressure is measured, the less elevation is evident. The raised pressure is thought to distort the periventricular tissue, including the parenchyma and vessels, either by compression or by stretching. There is loss of tissue elasticity and/or atrophy caused by the pressure forces acting on the brain parenchyma as well as ischemia from damage to blood vessels. This results in a state of normal CSF pressures that result in a reversal of the gradient of pressure and stress at the brain periphery or cerebral mantle. , $27,29,30,51,54,55,62^{2}$

\section{Interstitial Fluid Pressure Increase}

It is thought that loss of elasticity in the brain parenchyma results in a pressure gradient between the ventricles and periventricular tissues. Indeed, there may also be a pressure gradient between convexity subarachnoid spaces and the brain parenchyma; the pulse waveform in CSF recordings appears to be slightly greater (although not always) than in parenchyma (see Fig. 2), but a pressure gradient between convexity and subarachnoid spaces has never been documented. Animal studies have demonstrated that disruption of the periventricular matrix integrity could result in pressure gradients favoring progressive ventriculomegaly ${ }^{56}$ (see Structural under Imaging Studies, below). Both situations may result in the movement of CSF into the parenchyma in the form of interstitial edema. The stagnation of excess fluid in the interstitial space disrupts the balance between hydrostatic pressures (driving fluid out of capillaries) and osmotic pressures (driving fluid into capillaries). There may be reversal of interstitial fluid flow, resulting in swelling of the extracellular space, in turn resulting in failure of drainage of vasoactive metabolites that may reduce local cerebrovascular reactivity. The accumulation of toxic metabolites in the interstitial fluid may also disrupt cell and blood vessel walls, resulting in further leakage of fluid into the interstitial space. ${ }^{42,62,69,75}$

\section{Cerebral Blood Flow \\ Watershed Ischemia}

There is evidence that the cerebral vasculature may be compromised in NPH. Positron emission tomography (PET), xenon-enhanced CT, and SPECT studies all indi- 
TABLE 1. Summary of relevant literature on imaging related to pathophysiological theories in NPH

\begin{tabular}{|c|c|c|c|}
\hline Authors \& Year & Method & Cases & Key Findings \\
\hline \multicolumn{4}{|l|}{ Guidelines } \\
\hline $\begin{array}{l}\text { Relkin et al., } \\
2005\end{array}$ & Lit review & Lit review & $\begin{array}{l}\text { CT/MRI evidence of ventricular enlargement not entirely attributable to cerebral atrophy/con- } \\
\text { genital enlargement \& absence of macroscopic obstruction of CSF flow (e.g., tumor). One } \\
\text { of the following supportive features: enlargement of temporal horns of lateral ventricle not } \\
\text { entirely attributable to hippocampal atrophy; callosal angle } \geq 40^{\circ} \text {; evidence of altered brain } \\
\text { water content, including periventricular signal changes not attributable to microvascular } \\
\text { ischemic changes on demyelination or on aqueductal/4th ventricular flow void on MRI. }\end{array}$ \\
\hline
\end{tabular}

\begin{tabular}{|c|c|c|c|}
\hline \multicolumn{4}{|l|}{ Structural imaging } \\
\hline $\begin{array}{l}\text { Sasaki et al., } \\
2008\end{array}$ & $\begin{array}{l}\text { Visual assess- } \\
\text { ments on MRI }\end{array}$ & $\begin{array}{r}14 \mathrm{NPH}(+ \\
12 \mathrm{HVs})\end{array}$ & Narrowing of CSF space at high convexity/midline present in pts w/ NPH as compared w/ HVs. \\
\hline $\begin{array}{l}\text { Holodny et al., } \\
1998\end{array}$ & $\begin{array}{l}\text { Visual assess- } \\
\text { ments on MRI }\end{array}$ & $\begin{array}{l}17 \mathrm{NPH}, 17 \\
\mathrm{AD}\end{array}$ & $\begin{array}{l}\text { Pts w/ AD had dilated perihippocampal fissures \& enlarged ventricles that were smaller than in } \\
\text { iNPH. Pts w/ iNPH had sig ventriculomegaly but small/normal-sized fissures. }\end{array}$ \\
\hline $\begin{array}{l}\text { Tullberg et al., } \\
2001\end{array}$ & $\begin{array}{l}\text { Visual assess- } \\
\text { ments on MRI }\end{array}$ & $34 \mathrm{NPH}$ & $\begin{array}{l}25 \text { shunt-responders, } 9 \text { nonresponders. No correlation btwn deep WMH \& poor outcome } \\
\text { postop. }\end{array}$ \\
\hline $\begin{array}{l}\text { Kitagaki et al., } \\
1998\end{array}$ & $\begin{array}{l}\text { Semiquantitative } \\
\text { \& volumetric } \\
\text { analyses on } \\
\text { MRI }\end{array}$ & $\begin{array}{l}11 \mathrm{NPH}, 11 \\
\quad \mathrm{AD}, 11 \\
\text { VD }\end{array}$ & $\begin{array}{l}4 \text { CSF compartments were assessed: ventricles, basal cistern, sylvian space, \& suprasylvian } \\
\text { subarachnoid space. In NPH, CSF vol was significantly } \uparrow \text { in ventricles \& } \downarrow \text { in superior } \\
\text { convexity \& medial subarachnoid spaces. Sylvian CSF vol was significantly } \uparrow \text { in NPH than } \\
\text { in AD. Basal cistern vol was comparable among the } 3 \text { groups. In NPH, focally dilated sulci } \\
\text { were observed over convexity/medial surface of hemisphere. }\end{array}$ \\
\hline Palm et al., 2006 & $\begin{array}{c}\text { Volumetric assess- } \\
\text { ments on MRI }\end{array}$ & $26 \mathrm{NPH}$ & $\begin{array}{l}\text { Volumetric assessments for total intracranial vol, ventricular vol, brain vol, \& pericerebral CSF } \\
\text { vol. No predictive value in differentiating NPH pts who were shunt-responsive from those } \\
\text { who were not. }\end{array}$ \\
\hline $\begin{array}{l}\text { DeVito et al., } \\
2007\end{array}$ & $\begin{array}{c}\text { Volumetric assess- } \\
\text { ments on MRI }\end{array}$ & $\begin{array}{r}11 \mathrm{NPH}(+ \\
14 \mathrm{HVs})\end{array}$ & Loss of caudate vol in pts w/ neuropsychology patterns consistent w/ Dx of iNPH. \\
\hline \multicolumn{4}{|l|}{ Cerebral blood flow } \\
\hline $\begin{array}{l}\text { Klinge et al., } \\
1999\end{array}$ & $\begin{array}{l}{\left[{ }^{15} \mathrm{O}\right] \mathrm{H}_{2} \mathrm{O} \text { PET \& }} \\
\text { acetazolamide }\end{array}$ & $\begin{array}{r}10 \mathrm{NPH}(+ \\
10 \mathrm{HVs})\end{array}$ & $\begin{array}{l}\text { Borderline preop CBF \& cerebrovascular reserve not predictive of outcome. } \downarrow \text { preop CBF not } \\
\text { predictive of a poor outcome. Postop cerebrovascular status did correlate w/ outcome; } \downarrow \\
\text { cerebrovascular reserve in early postop period related to poor late outcome, early } \uparrow \text { cere- } \\
\text { brovascular reserve related to good outcome. }\end{array}$ \\
\hline $\begin{array}{l}\text { Klinge et al., } \\
2008\end{array}$ & {$\left[{ }^{15} \mathrm{O}\right] \mathrm{H}_{2} \mathrm{O} \mathrm{PET}$} & $65 \mathrm{NPH}$ & $\begin{array}{l}{\left[{ }^{15} \mathrm{O}\right] \mathrm{H}_{2} \mathrm{O} \text { uptake was correlated w/ preop clinical scores, graded according to a modified Stein }} \\
\text { \& Langfitt score. Diffs in uptake in pre- \& postshunt treatment study after } 7-10 \text { days in pts w/ } \\
\& \text { w/o clinical improvement were studied. } \uparrow \text { clinical score significantly correlated w/ } \downarrow \text { tracer } \\
\text { uptake in mesial frontal \& anterior temporal areas. In mesial frontal areas, tracer uptake } \\
\text { showed sig reciprocal changes in clinically improved vs unimproved pts. }\end{array}$ \\
\hline $\begin{array}{l}\text { Owler et al., } \\
2004^{57}\end{array}$ & $\begin{array}{l}{\left[{ }^{15} \mathrm{O}\right] \mathrm{H}_{2} \mathrm{O} \text { PET \& }} \\
\mathrm{MR} \text { coregistra- } \\
\text { tion }\end{array}$ & $\begin{array}{l}17 \mathrm{NPH}(12 \\
\text { iNPH, } 5 \\
\text { sNPH) }\end{array}$ & $\begin{array}{l}\text { Sig decrease in global CBF results for cerebrum \& cerebellum of NPH pts. No sig diff in rCBF } \\
\text { results in WM ROIs btwn NPH \& controls. rCBF in deep gray matter structures significantly } \\
\text { reduced (thalamus, putamen, head of caudate). }\end{array}$ \\
\hline $\begin{array}{l}\text { Momjian et al., } \\
2004\end{array}$ & $\begin{array}{l}{\left[{ }^{15} \mathrm{O}_{\mathrm{H}} \mathrm{H}_{2} \mathrm{O} \text { PET \& }\right.} \\
\mathrm{MR} \text { coregistra- } \\
\text { tion }\end{array}$ & $\begin{array}{r}12 \mathrm{NPH}(+ \\
10 \mathrm{HVs})\end{array}$ & $\begin{array}{l}\text { Percentage change of WM CBF was in the form of a U-shaped relationship w/ distance from } \\
\text { the ventricles. WM CBF was generally reduced in NPH pts w/ max reduction adjacent to } \\
\text { ventricles w/ progressive normalization toward the subcortical WM. }\end{array}$ \\
\hline $\begin{array}{l}\text { Tullberg et al., } \\
2004\end{array}$ & SPECT & $28 \mathrm{NPH}$ & $\begin{array}{l}14 \text { of } 16 \text { pts presenting w/ impaired wakefulness improved postop. } \downarrow \text { relative rCBF in anterior } \\
\text { cingulate cortex of pts w/ impaired wakefulness. Sig postop increase in relative rCBF in } \\
\text { thalamic, frontal, \& hippocampal gray matter regions. Increases in relative rCBF in frontal } \\
\text { association cortex were associated w/ improvements of Sx of impaired wakefulness. }\end{array}$ \\
\hline $\begin{array}{l}\text { Bradley et al., } \\
\quad 1996\end{array}$ & $\begin{array}{l}\text { CSF SV \& aque- } \\
\text { ductal CSF flow } \\
\text { void }\end{array}$ & $18 \mathrm{NPH}$ & $\begin{array}{l}\text { Analysis group comprised } 18 \text { pts who underwent surgery. All pts w/ CSF SV >42 } \mu \text { l were } \\
\text { shunt-responders. }\end{array}$ \\
\hline $\begin{array}{l}\text { Kahlon et al., } \\
2007\end{array}$ & $\begin{array}{l}\text { Cine phase- } \\
\text { contrast MRI }\end{array}$ & $38 \mathrm{NPH}$ & $\begin{array}{l}\text { Pts divided into } 3 \text { SV groups: low }(0-50 \mu \mathrm{l}) \text {, middle }(51-100 \mu \mathrm{l}), \& \text { high }(>100 \mu \mathrm{l}) \text {. No correlation } \\
\text { found btwn statistically sig improvements in clinical outcome assessment \& SV in any of the } \\
\text { groups. }\end{array}$ \\
\hline $\begin{array}{l}\text { Balédent et al., } \\
\quad 2004\end{array}$ & $\begin{array}{l}\text { CSF \& CBF } \\
\text { phase-contrast } \\
\text { MRI }\end{array}$ & $\begin{aligned} 12 \mathrm{CH}(+ \\
16 \mathrm{HVs})\end{aligned}$ & Pts w/ CH characterized by hyperdynamic CSF flow through aqueduct. \\
\hline
\end{tabular}


» CONTINUED FROM PAGE 3

TABLE 1. Summary of relevant literature on imaging related to pathophysiological theories in NPH

\begin{tabular}{|c|c|c|c|}
\hline Authors \& Year & Method & Cases & Key Findings \\
\hline \multicolumn{4}{|l|}{$\begin{array}{l}\text { Cerebral blood flow } \\
\text { (continued) }\end{array}$} \\
\hline $\begin{array}{l}\text { Bateman \& } \\
\text { Loiselle, } \\
2007\end{array}$ & $\begin{array}{l}\text { Retrospectively } \\
\text { cardiac-gated } \\
\text { phase-contrast } \\
\text { flow quanti- } \\
\text { fication MR } \\
\text { sequence }\end{array}$ & $\begin{array}{l}32 \mathrm{NPH} \\
12 \mathrm{AD} \\
(+12 \\
\mathrm{HVs})\end{array}$ & $\begin{array}{l}20 \text { shunt-responders, } 12 \text { nonresponders. MR flow quantification performed for degree of } \\
\text { ventricular enlargement, sulcal compression, WM disease, total blood inflow, sagittal } \\
\text { sinus outflow, aqueduct SV, relative compliance ratio, \& arteriovenous delay. NPH pts had } \\
\text { significantly } \uparrow \text { aqueduct SV of } 210 \% \text { compared to controls. Total blood inflow, sagittal sinus } \\
\text { outflow, relative compliance ratio, \& arteriovenous delay were all significantly } \downarrow \text { in the pt } \\
\text { group compared to controls. }\end{array}$ \\
\hline $\begin{array}{l}\text { Scollato et al., } \\
2008\end{array}$ & $\begin{array}{l}\text { Cine phase- } \\
\text { contrast MRI }\end{array}$ & $9 \mathrm{NPH}$ & $\begin{array}{l}\text { SV changes in NPH pts who refused any intervention. SV dependent on time from onset of Sx, } \\
\uparrow \text { during the } 1 \text { st } 18-20 \text { mos from onset of Sx, w/ plateau period \& then decline in the follow- } \\
\text { ing } 18-20 \text { mos to a more precipitous drop in the } 12 \text { mos thereafter. }\end{array}$ \\
\hline \multicolumn{4}{|l|}{ Toxic metabolites } \\
\hline $\begin{array}{l}\text { Silverberg et al., } \\
2008\end{array}$ & Double-blind, RCT & $215 A D$ & $\begin{array}{l}\text { Participants received either a low-flow VP shunt or a sham (occluded) shunt for } 9 \text { mos. Study } \\
\text { results did not demonstrate any benefit in low-flow CSF shunting in pts w/ mild to severe AD. }\end{array}$ \\
\hline $\begin{array}{l}\text { Leinonen et al., } \\
\qquad 2008\end{array}$ & $\begin{array}{l}{\left[{ }^{11} \mathrm{C}\right] \mathrm{PiB}} \\
\text { PET }\end{array}$ & $10 \mathrm{NPH}$ & $\begin{array}{l}\text { Significantly higher }\left[{ }^{11} \mathrm{C}\right] \mathrm{PiB} \text { uptake in the frontal, parietal, \& lateral temporal cortices \& in the } \\
\text { striatum of pts w/ } A \beta \text { aggregates in the frontal cortical biopsy specimen compared to pts w/o } \\
\text { frontal } A \beta \text { aggregates. }\end{array}$ \\
\hline
\end{tabular}

$A \beta=$ amyloid $-\beta ; A D=$ Alzheimer's disease; $C H=$ communicating hydrocephalus; diff = difference; $D x=$ diagnosis; $H V=$ age-matched healthy volunteer; lit = literature; $\mathrm{pt}=$ patient; $\mathrm{rCBF}=$ regional $\mathrm{CBF} ; \mathrm{RCT}=$ randomized controlled trial; sig = significant; $\mathrm{sNPH}=$ secondary $\mathrm{NPH} ; \mathrm{SV}=$ stroke volume; $\mathrm{Sx}=$ symptoms; $\mathrm{VD}=$ vascular dementia; $\mathrm{WM}=$ white matter; $\mathrm{WMH}=\mathrm{WM}$ hyperintensities; $\uparrow=$ increased; $\downarrow=$ decreased.

cate widespread cortical and subcortical hypometabolism and impaired global CBF. ${ }^{76,75}$ This may result in dysfunctional regional cerebral autoregulation, and watershed ischemia may occur in the corona radiata between territories supplied by perforators from the middle cerebral artery and medullary branches from the pial arteries ${ }^{53,54,55}$ (see Fig. 3). There has, however, been a frustrating lack of congruence within the group of studies examining CBF in NPH. The main problems are the diversity of different techniques employed for the measurement of CBF. There are no gold standard tests for the assessment of CBF as a diagnostic or prognostic tool. Most studies have included both idiopathic and secondary forms of NPH. Only a few studies have attempted to combine $\mathrm{CBF}$ measurement with structural imaging co-registration to achieve a good anatomical basis for comparisons of $\mathrm{CBF}$ data. ${ }^{55,57}$

\section{Vascular Disease}

The coincidental presence of deep white matter hyperintensities on imaging in some patients with NPH has also provoked debate about the possibility of cerebral small vessel disease and vascular encephalopathy. ${ }^{18,26}$ It is thought that ventricular expansion may distort the connections and/or blood vessels between the basal ganglia and frontal cortex. This distortion may disrupt white matter tracts involved in frontal executive function, gait, and micturition, producing the symptoms of gait apraxia and urinary incontinence. The stretching of blood vessels may also produce multiple areas of deep lacunar infarction. This may result in ischemia of the white matter areas supplied by these blood vessels. The parenchymal architecture may also be affected by the presence of these lacunar infarctions, leading to a loss of elasticity. ${ }^{21}$ Such a progression may allow progressive ventricular expansion in the context of normal intracranial pressures, which is a particular phenomenon noted in NPH. It is thought that despite normal baseline pressures, abnormal CSF pressure spikes called B waves exert intermittent high pressure on the periventricular tissue, especially during REM sleep. ${ }^{20}$ Overlapping vascular diseases with CSF disorder has been studied during infusion studies using transcranial Doppler ultrasonography. ${ }^{16}$ Those patients with increased resistance to CSF outflow (Rcsf) had more frequently normal autoregulation of $\mathrm{CBF}$ and those with normal Rcsf (normal CSF circulation) had more frequently disturbed autoregulation-probably due to vascular disease.

\section{CSF Flow}

\section{CSF Hydrodynamics}

Normal pressure hydrocephalus is thought to be a form of CSF circulation disorder, involving an imbalance between CSF production, circulation, and reabsorption. ${ }^{63}$ The resulting excess accumulation of CSF is thought to result in ventriculomegaly. In NPH, however, unlike other forms of hydrocephalus, the CSF pressure is not abnormally raised, which implies that such a simplistic hydrodynamic theory would be insufficient to explain the pathophysiology of this condition. Historically, increased resistance to CSF outflow measured during an infusion test been implicated as a factor responsible for development of hydrocephalus, ${ }^{9}$ although this has been challenged in recent studies. ${ }^{84}$

It has been suggested that abnormalities of the brain parenchyma that naturally occur in the aging brain (loss of elasticity of the neuropil, extracellular matrix, and parenchyma) also contribute to the development of NPH. These 


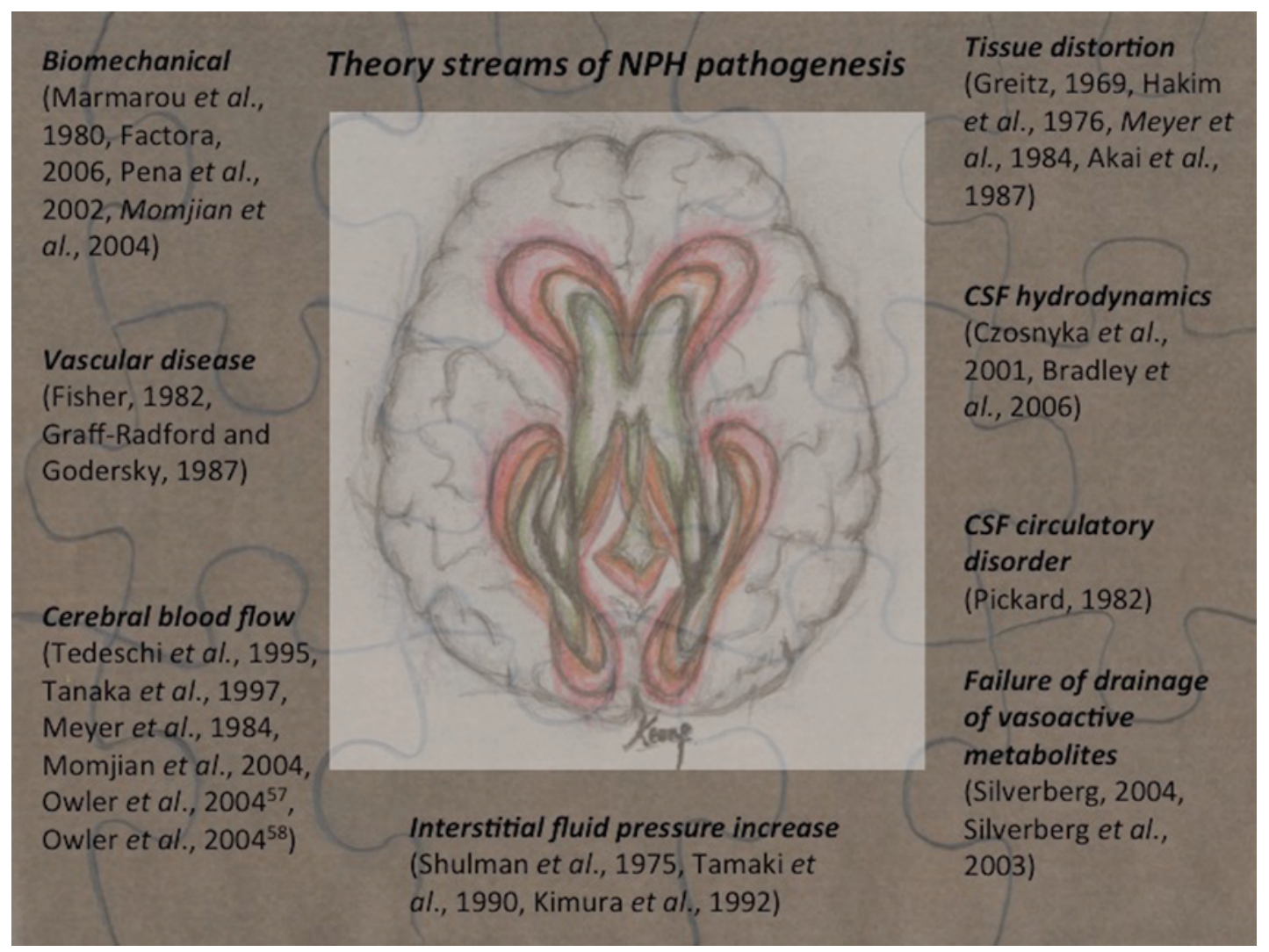

FIG. 1. Theory streams of NPH pathogenesis. Copyright Nicole C. Keong. Published with permission.

abnormalities are thought to make the cerebral mantle more susceptible to B waves, which slowly increase ventricular size by exerting intermittent high pressures on the brain parenchyma, resulting in ischemic damage. These pressures are thought to behave in a "water hammer" fashion. Therefore, in addition to disturbances within the CSF circulation, there may also be an imbalance between the forces driving progressive ventriculomegaly and the architectural forces within the brain parenchyma that should naturally oppose this. An additional force driving ventricular enlargement may be increased amplitude of the ICP pulse waveform ${ }^{19}$ (see Fig. 4), but this hypothesis is not supported by any observable correlation between ventricular dilation and magnitude of such amplitude measured during infusion studies or overnight monitoring of ICP.

There is physiological evidence to suggest that such an imbalance exists. Czosnyka et al. ${ }^{15}$ examined the question of age dependence of CSF pressure-volume compensation by performing CSF infusion studies in a group of patients with symptomatic hydrocephalus and normal ICP. They demonstrated Rcsf increased in a nonlinear fashion with advancing age and was associated with a decrease in the CSF production rate, which also occurred with increasing age. Both the pulse amplitude of the ICP waveform and the slope of the amplitude-ICP regression line increased significantly with advancing age. There was a nonlinear increase in the elastance coefficient with age, and this was thought to represent progressive brain parenchymal stiffness.

\section{Failure of Drainage of Vasoactive Metabolites}

Abnormalities in CSF production and turnover may also lead to inefficient or failed clearance of toxic molecules. Silverberg and colleagues ${ }^{71,73}$ proposed that an inability to clear potentially toxic metabolic products, such as amyloid- $\beta$ peptides and tau protein, could lead to an increase in their concentration in brain interstitial fluid, creating a potentially hostile milieu for neuronal function and survival. It is further proposed that the two changes noted in aging, reduced CSF production and increased Rcsf, may be implicated in the pathophysiology of Alzheimer's disease and NPH. A predominance of reduced CSF production and turnover may manifest as Alzheimer's disease. Conversely, NPH may result from a predominant increase in Rcsf. There may be a disease spectrum that includes a subset of patients who either have both conditions or have risks of developing both even if one process is predominant.

This implies that CSF diversion (i.e. the placement of a shunt) may be helpful in other conditions within the dementia spectrum. Indeed, it may be more accurate to describe a disease component remediable to shunting that occurs predominantly in classical NPH but may also be present in a subset of patients with an overlap of conditions. Silverberg et al. ${ }^{72}$ then published the results of a prospective, randomized, double-blinded, placebo-controlled trial evaluating the safety and effectiveness of a surgically implanted shunt in patients with probable Alzheimer's disease. The trial involved 215 patients. Participants re- 

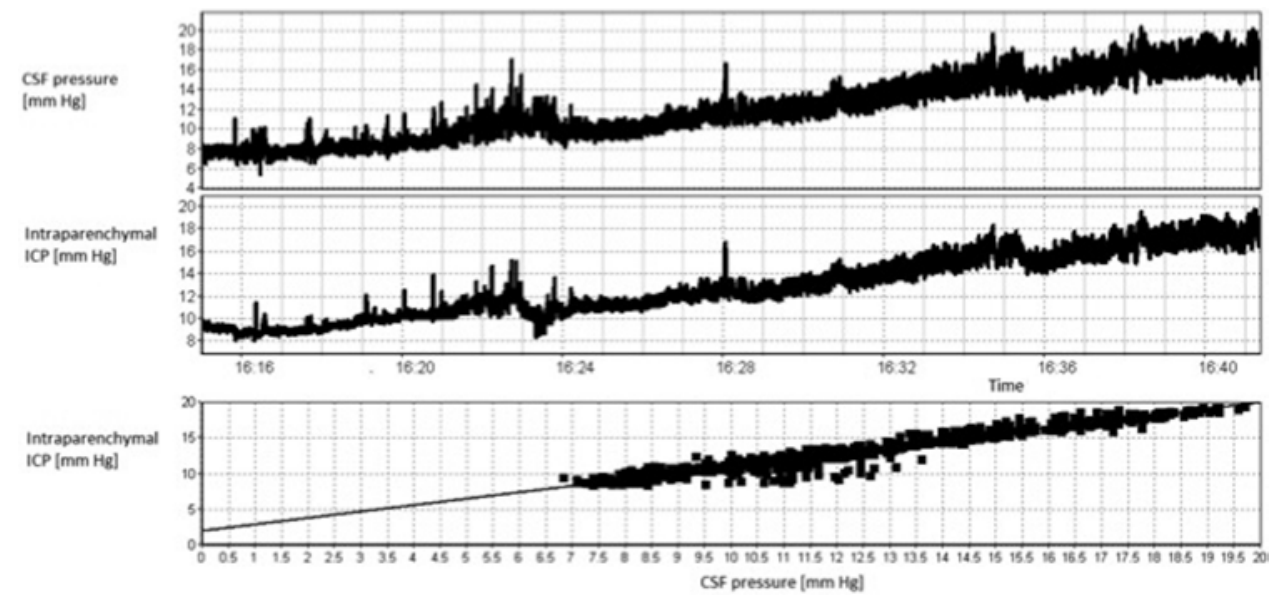

FIG. 2. Simultaneous recording of lumbar CSF pressure and intraparenchymal ICP in a patient with probable iNPH undergoing a CSF infusion study. Both pressures are very well correlated $(R=0.98)$, and there was no systematic difference of recording from both transducers, neither in mean pressure values nor incidence of slow vasogenic waves. Only the pulse waveform in CSF pressure was slightly greater than that in intraparenchymal pressure. Time is shown in hours and minutes.

ceived either a low-flow ventriculoperitoneal (VP) shunt or a sham (occluded) shunt for 9 months. The results of the study did not demonstrate any benefit for low-flow CSF shunting in patients with mild to severe Alzheimer's disease. It is unclear whether increased clearance of toxic macromolecules through CSF diversion was insufficient to improve the condition or inadequate clearance was achieved due to established deposition of macromolecules

\section{SRoR[\%]}

\section{$p<0.007$}

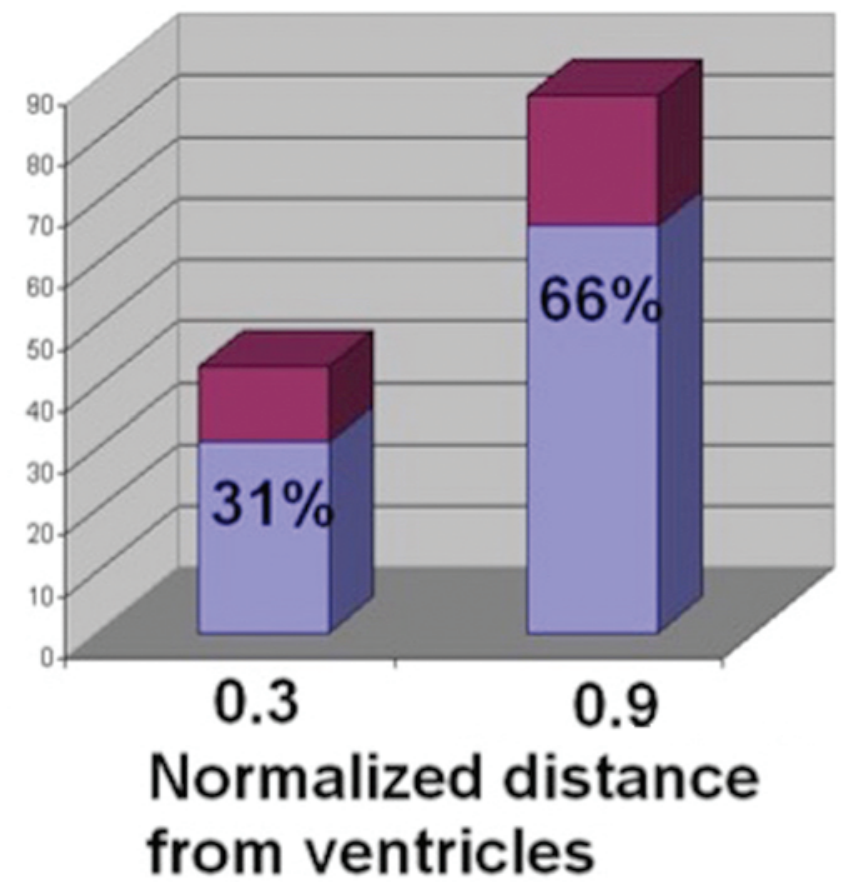

FIG. 3. Static rate of autoregulation (SRoR) in white matter at 2 distances from the ventricular walls. $100 \%$ represents ideal autoregulation, $0 \%$ totally defective autoregulation. A distance of 0.3 is located in probable watershed areas, whereas 0.9 is close to gray matter. Graph based on data from Momjian et al. ${ }^{55}$ into fibrillary tangles. Indeed, it may be that a sufficient level of CSF circulatory disorder is required to benefit from shunting, although the threshold of Rcsf that is associated with improvement from shunting still continues to provoke debate.

\section{Imaging Studies}

For key references, see Table 1.

\section{Structural}

Although many authors have approached the subject of tissue distortion in the pathophysiology of $\mathrm{NPH}, 54,55$ Hakim's original hypothesis introduced the concept of biomechanics to this field by characterizing brain parenchyma as akin to "an open cell sponge made of viscoelastic material." Research in this field has focused on assessing intracranial pulse pressures, transmantle pressure gradients, and similar individual parameters while attempting to translate these findings into parallel theories of ventricular enlargement, with mixed results. In particular, research studies in human and animal communicating hydrocephalus aiming to measure a transmantle pressure gradient have consistently failed to do so, making progressive ventriculomegaly in such conditions somewhat contradictory.

In more recent work employing biomechanics, Pena et al. ${ }^{61}$ developed a computer simulation model of acute obstructive hydrocephalus using Hakim's theory as a starting point to understand why periventricular edema was most prominent in the anterior and posterior horns of the lateral ventricles. A finite-element mesh was created based on the understanding of deformation mechanics as described by Biot's equations, modeling the brain parenchyma as a 2-phase poroelastic matrix saturated by interstitial fluid. The model demonstrated that the characteristic distribution of periventricular edema in acute hydrocephalus depended upon increased intraventricular pressure as well as ventricular geometry. Expansive (tensile) stresses were seen in convex geometry of the regions surrounding the 


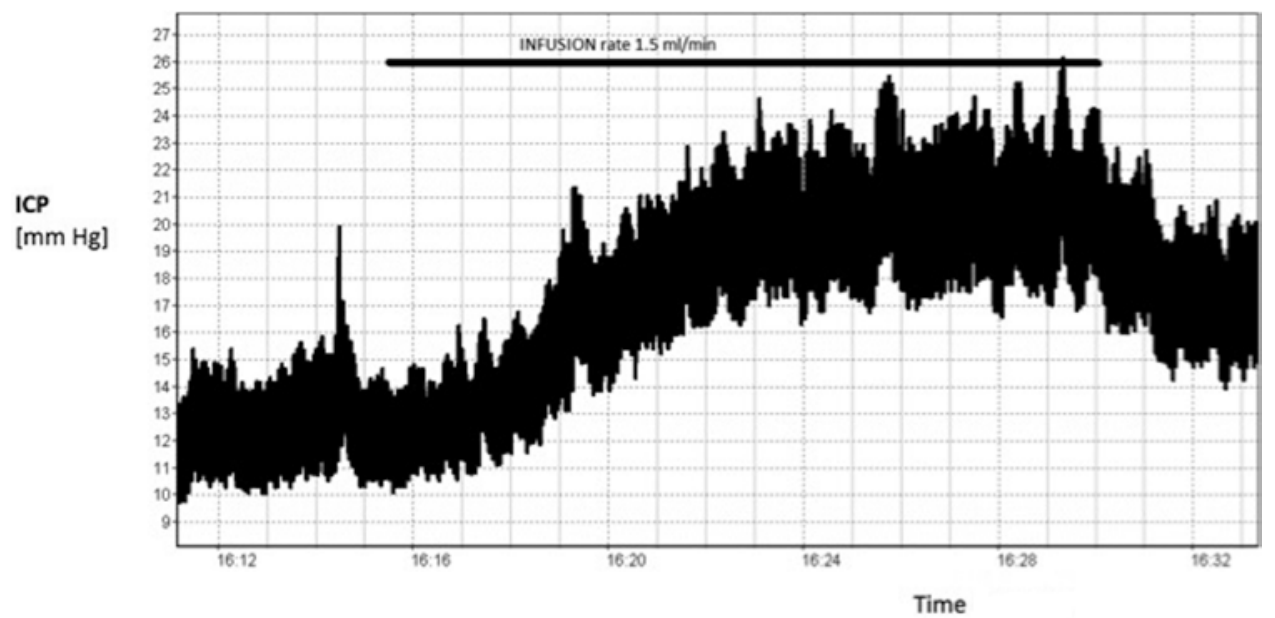

FIG. 4. A CSF infusion test in a patient diagnosed with iNPH. The baseline pressure was normal at $12 \mathrm{~mm} \mathrm{Hg}$ and resistance to CSF outflow was normal at $6 \mathrm{~mm} \mathrm{Hg} /(\mathrm{ml} / \mathrm{min}$ ), but the pulse amplitude was increased (baseline $4.5 \mathrm{~mm} \mathrm{Hg}$, plateau $6.2 \mathrm{~mm} \mathrm{Hg}$ ). A shunt was placed, and the patient's clinical condition improved. However, in larger-scale analyses of 325 patients audited in the Cambridge multidisciplinary Hydrocephalus Clinic, the association between improvement after CSF shunting and magnitude of pulse amplitude is not as convincing. Time is shown in hours and minutes.

anterior and posterior horns whereas compressive stresses were created in the concave geometry in the region of the body of the ventricles. Such precedents found in modeling have direct relevance to the diffusion tensor imaging (DTI) hypotheses of white matter injury patterns reported in NPH.

Further work by this group directly addressed the more relevant question to NPH, i.e. that of progressive ventricular enlargement in the context of communicating hydrocephalus and a normal mean ICP. ${ }^{62}$ The results of computer simulations in this group demonstrated that a relative reduction in intraparenchymal fluid pressure (i.e., interstitial fluid pressure) coupled with low tissue elasticity in the periventricular area could produce significant ventricular enlargement and periventricular solid stress concentrations. The results appeared to support the hypothesis that a reversal of CSF transependymal flow would result in a reversal of interstitial fluid flow into the parenchyma and absorption of CSF by tissue. This phenomenon, coupled with parallel development of low tissue elasticity possibly due to ischemia or atrophy, would then produce a pressure gradient between CSF spaces and the cerebral mantle (i.e., an intramantle pressure gradient) rather than a transmantle pressure gradient. This sequence of events would be consistent with the development of progressive ventricular enlargement in the context of a communicating hydrocephalus with normal ICPs. The hypothesis of an intramantle pressure gradient has been subsequently confirmed by other methodologies.

Using a rat model of hydrocephalus, Nagra et al. ${ }^{56}$ subsequently demonstrated a molecular mechanism for the mathematical model proposed by Pena. In this study, beta1 integrin interstitial matrix interactions were disrupted by injections of anti-integrin antibodies resulting in a decline in periventricular pressures relative to preinjection values, whereas ventricular pressures were significantly greater that the periventricular interstitium (estimated ventricular to periventricular gradients of up to $4.3 \mathrm{~cm}$
$\mathrm{H}_{2} \mathrm{O}$ ). The group therefore concluded that a disturbance in periventricular matrix integrity could generate pressure gradients favorable for ventricular expansion. The alteration of mechanical properties of brain tissue in NPH has been demonstrated using MR elastography, a noninvasive method of measuring brain mechanics in vivo, in a study by Streitberger et al. ${ }^{74}$ The authors found a loss of rigidity of up to $20 \%$ in brain tissue of patients with NPH compared with controls. Decreases in viscoelastic properties in NPH patients were more pronounced in the periventricular regions, consistent with Pena's hypothesis. Further work from the same group confirmed viscoelastic parameters to be significantly decreased compared with controls, with significant improvement in alpha but not mu parameters following successful shunt placement, confirming alteration of biomechanical properties of brain tissue due to intervention. ${ }^{22} \mathrm{An}$ appreciation for such precedents in mathematical and biomechanical findings is therefore crucial to inform the interpretation of DTI findings of white matter injury patterns due to the complex nature of the NPH syndrome, with some types of white matter injury hypothesized to be more reversible than others.

Several research groups have focused on employing reproducible quantitative assessments based on more traditional anatomical MRI studies and have shown correlations between key structural features and the diagnosis of NPH. Sasaki et al. ${ }^{67}$ used a visual assessment method to assess the narrowing of the CSF space at the high convexity/midline, that is thought to be present in patients with iNPH. The method was applied to axial and coronal MR images. Although the authors successfully demonstrated that there was a difference between these areas in iNPH patients as compared with age-matched healthy volunteers, there were several limitations with the study. The patient cohort was relatively small with a wide age variation. Other subgroups were not included, particularly those with conditions such as Alzheimer's disease and multi-infarct dementia. The authors also acknowledge that it was 
difficult to ascertain whether the finding would be found in almost all patients with iNPH or to determine whether similar findings were occasionally seen in the aging population or individuals with other pathologies without iNPH symptoms. Nevertheless, their work illustrated the potential role of a straightforward measurement technique based on readily accessible patient imaging data. Significant differences have been found between the degree of dilation of perihippocampal fissures in patients with Alzheimer's disease as compared with those with iNPH. A study by Holodny et al. ${ }^{35}$ demonstrated that patients with Alzheimer's disease had dilated perihippocampal fissures and enlarged ventricles that were smaller than in iNPH, whereas patients with iNPH had significant ventriculomegaly but small or normal-sized fissures. In a prospective study of $100 \mathrm{iNPH}$ patients, SINPHONI, an MRI-based diagnosis, with evidence of DESH, in which tight high convexity and medial subarachnoid spaces and enlarged sylvian fissures are associated with ventriculomegaly, achieved a favorable outcome in $69 \%-77 \%$ of patients, depending on which outcome grading scale was administered. ${ }^{32}$

There has been controversy regarding other changes regularly seen on MRI in patients presenting with NPH symptomatology. Periventricular lucency has been variously thought to represent edema or atrophy. The finding of deep white matter hyperintensities is believed to be associated with cerebrovascular disease. It has been suggested that these areas represent multiple small deep cerebral infarctions in the periventricular white matter and basal ganglia and may be a result of episodes of hypertension. ${ }^{25,26}$ White matter hyperintensities have also been thought to represent areas of lacunar infarction from distortion of tissue and blood supply in areas susceptible to stretching from progressive ventricular enlargement. The imaging finding of white matter hyperintensities in a patient with NPH has been shown to be inversely correlated with responsiveness to CSF shunting. ${ }^{46}$ Nevertheless, other studies have demonstrated that the presence of these lesions may not predict poor outcome following shunt surgery. Using conventional MRI sequences, Tullberg et al. ${ }^{81}$ examined these lesions and other MR variables in a group of NPH patients undergoing surgery. The study showed no correlation between the presence of these parameters and poor outcome following surgery, casting doubt on the use of these imaging markers as exclusion criteria for the consideration of surgery. However, there was a postoperative reduction in the width of periventricular lucency at the frontal horns in the patients whose condition improved.

In a further study, Tullberg et al. ${ }^{79}$ investigated the relationship between 10 ventricular CSF markers, periventricular white matter lesions, and postoperative clinical outcome in 35 patients who were undergoing shunt placement for treatment of NPH. They found that higher ventricular CSF levels of neurofilament protein (NFL), an axonal marker, correlated with more extensive periventricular white matter hyperintensities. A larger postoperative reduction in NFL correlated with a larger reduction in periventricular hyperintensities and a more pronounced overall improvement, as measured by 12 clinical symptoms and signs. However, variations in ventricular size were not associated with CSF concentrations of any marker. The authors concluded that the periventricular white matter hyperintensities seen in NPH were a marker of ongoing periventricular neuronal dysfunction and were reversible following surgery. Akiguchi et al. ${ }^{2}$ also found the phenomenon of reversible white matter lesions in a study in which the changes in the motor symptoms of $17 \mathrm{iNPH}$ patients were examined before and after surgery. Most of the patients in this cohort had parkinsonism (71\%); fewer patients had other existing comorbidities, such as small-vessel diseases (29\%), hypertension (41\%) or diabetes $(35 \%)$. White matter lesions were identified on CT or MR images in $88 \%$ of the patients. Following surgery, there was significant improvement in ventriculomegaly and mean total scores for white matter lesions as well as clinical improvement. Such studies provide support for Hakim's original hypothesis of tissue distortion rather than a pure CSF circulation disorder or hypertensive vascular disease.

Quantitative structural assessments have also been employed in the measurement of intracranial CSF compartments. As a significant degree of ventriculomegaly remains one of the most striking features of patients presenting with symptoms of iNPH, it would not be unreasonable to make the clinical assumption that the order of magnitude of this finding may correlate with shunt-responsiveness. Kitagaki et al. ${ }^{43}$ investigated the morphological features and volume of the CSF space in patients with iNPH compared with those with other dementias using MRI. Four CSF compartments (the ventricle, basal cistern, sylvian space, and suprasylvian subarachnoid space) were measured using semiquantitative and volumetric analyses of coronal T1weighted MR images. The study compared results in 11 shunt-responsive patients with iNPH with those in 11 ageand sex-matched patients with Alzheimer's disease and in 11 patients with vascular dementia. The results demonstrated that the CSF volume was significantly increased in the ventricles and decreased in the superior convexity and medial subarachnoid spaces in iNPH patients compared with patients with other dementias. The sylvian CSF volume in patients with iNPH was also significantly greater than in patients with Alzheimer's disease. The volume of the basal cistern was comparable among the three groups. In several patients with idiopathic NPH, focally dilated sulci were observed over the convexity or medial surface of the hemisphere. The authors concluded that findings of enlarged basal cisterns and sylvian fissures and of focally dilated sulci supported, rather than excluded, the diagnosis of shunt-responsive iNPH.

The strength of this study was the comparison between the 3 groups of patients-those with iNPH, those with Alzheimer's disease, and those with vascular dementia-although the numbers of patients in each group were relatively small. The main limitation of this study was the lower-order nature of supplementary tests used to confirm each of the diagnoses, for example the use of the Mini-Mental State Examination (MMSE) in place of more extended neuropsychological testing. Lumbar punctures were used instead of CSF infusion studies or extended lumbar drainage to assess suitability for shunt surgery. Guidelines published on this method have concluded that a lumbar puncture with withdrawal of $40-50 \mathrm{ml}$ of CSF cannot be used as an exclusion test due to its low sensi- 
tivity (published sensitivity rates range from $26 \%$ to $61 \%$ ) and variable specificity (range 33\%-100\%), making it suitable only as an initial investigative tool. ${ }^{28,49,50,83}$ Moreover, sensitivity and specificity have been demonstrated to differ depending on which individual variables and type of iNPH score were used for correlation. The use of decisiontree analyses with lumbar puncture have been shown to increase sensitivity to $82.5 \%$ while maintaining a reasonable specificity of $65 \%,{ }^{36}$ but such refinements were not employed here. These limitations may have influenced the recruitment of patients to the iNPH group by preselecting only a small subgroup of patients with the disease. Nevertheless, the authors did demonstrate a reliable method of visual rating and volumetry for the assessment of CSF spaces in this condition. Their conclusions suggest that this condition is caused by a suprasylvian subarachnoid block, which does support the theory of a CSF circulation disorder as the underlying pathophysiological mechanism in INPH.

In a study by Palm et al., ${ }^{60} 26$ patients with a clinical or radiological suspicion of NPH underwent MRI in addition to standard clinical assessments of gait, bladder function, and cognition. All patients were offered intervention, and clinical follow-up was then assessed at 1 year following shunt surgery. Volumetric assessment was performed for the following compartments - total intracranial volume, ventricular volume, brain volume, and pericerebral CSF volume. This allowed the following indices to be determined-ventricular volume ratio, brain volume ratio, pericerebral CSF volume ratio, and the ratio of ventricular volume to pericerebral CSF volume.

The authors concluded that volumetric assessment had no predictive value in differentiating between NPH patients who were shunt-responders versus those who were not. The main limitations of this study were the lack of comparison data in the form of age-matched healthy controls, patients with possible NPH who did not undergo surgery, or patients with other pathologies such as cortical atrophy or Alzheimer's disease. Imaging was also acquired at 2 different field strengths, $0.5 \mathrm{~T}$ or $1.5 \mathrm{~T}$, and it was unclear if this could have influenced intra- and interpatient serial imaging comparisons. However, the volumetric assessment technique was demonstrated to have a high intrarater reliability based on the reanalysis of 5 of the 26 patient scans. Despite the limitations of this study, the work does contribute to the ongoing debate regarding the pathophysiology of NPH. The lack of correlation between volumetric changes in intracranial CSF compartments in shunt-responsive patients suggests that understanding changes in other intracranial structures, such as white matter tract distortion, may be the key to explaining the evolution and, therefore, reversibility of NPH symptomatology.

Despite the fact that NPH patients regularly present with a relatively insidious history of gait and cognitive disturbance, supplementary testing has revealed traits characteristic of this disease. Neuropsychological assessments have demonstrated that the cognitive deficits in NPH follow of a pattern of a subcortical dementia in contrast to the cortical deficits of Alzheimer's and other types of dementia. Patients with NPH often demonstrate a frontal dysexecutive syndrome, whereas this diagnosis would be considered unlikely in the context of a focal aphasia, agnosia, or similar cortical deficit. Mood changes such as apathy may also be present. This suggests that the cognitive symptom in iNPH may be attributable to a disruption in the subfrontal white matter connections, the limbic connections, or indeed, the reciprocal connections between the frontal lobe and the deep gray matter structures. This is in contrast to the atrophy and destruction of the medial temporal lobe structures seen in Alzheimer's disease that may explain the more devastating cognitive decline associated with the latter pathology. Parallel advances in imaging have provided supportive evidence for these contrasts. A voxel-based morphometric study by DeVito et al. ${ }^{17}$ demonstrated loss of caudate volume in patients with neuropsychological patterns consistent with a diagnosis of iNPH.

\section{Cerebral Blood Flow}

Vascular status has long been a subject of research interest in a wide variety of areas within the field of NPH, including prognostication, shunt-responsiveness, and increasing the understanding of the pathophysiological changes associated with the disease. Despite the large numbers of cases studied, there is still great variationand, in fact, contradiction-in the results generated by CBF studies. This is partly due to the fact that in addition to the range of clinical assessment techniques employed by different research groups, varying techniques have been used to measure CBF. Xenon-CT, SPECT, and PET studies have all been used as investigative tools. ${ }^{44,45,57,80}$ In parallel to this, various methods for characterizing cerebrovascular reserve including acetazolamide and xenon inhalation have been established. Therefore, the challenge is to extract the individual contributions of the multitude of studies toward the greater understanding of the NPH disease spectrum.

The measurement of CBF using $\left[{ }^{15} \mathrm{O}\right] \mathrm{H}_{2} \mathrm{O}$-PET coupled with acetazolamide challenge for the estimation of cerebrovascular reserve was the method employed by Klinge et al. ${ }^{44}$ in a research study examining those parameters preand postoperatively ( 7 days and 7 months after surgery). Both regional and global $\mathrm{CBF}$ analysis was performed, with regions of interest defined corresponding to the territories supplied by the anterior, middle, and posterior cerebral arteries. Interestingly, baseline preoperative CBF and cerebrovascular reserve were found not to be predictive of outcome. Reduced preoperative $\mathrm{CBF}$ was not predictive of a poor outcome. However, postoperative cerebrovascular reserve status did correlate with outcome; reduced cerebrovascular reserve in the early postoperative period was related to poor late outcome whereas an early increase was related to good outcome.

The main limitations of the study were the relatively small patient group, resulting in 5 patients showing improvement and 5 who did not and the significant age gap between the patients (mean age $67 \pm 10$ years) as compared with the healthy volunteers (mean age $25 \pm 3$ years). Because patients served as their own controls (i.e., baseline vs 7-day and 7-month postoperative scans), the size of the patient group was reasonable, but the age gap be- 
tween the patient and volunteer groups may have played a substantial role in influencing the analysis. Although no decrease in global CBF has been demonstrated in healthy aging in some studies, ${ }^{53}$ the relationship between age and blood flow is still debated. The variations in CBF in the normal aging brain or in patients with other comorbidities were not determined in this study. In a further PET study, Klinge et al..$^{45}$ correlated $\left[{ }^{15} \mathrm{O}\right] \mathrm{H}_{2} \mathrm{O}$ uptake with the preoperative clinical scores of 65 patients with NPH, graded according to a modified Stein and Langfitt score. Differences in the uptake in the pre- and postshunt treatment study after 7 to 10 days in patients with and without clinical improvement were studied. The data were retrospectively analyzed for the correlation between the patients' functional status and local blood flow as measured by tracer uptake before shunt treatment and 7-10 days after treatment. The authors found that a higher clinical score significantly correlated with reduced tracer uptake in mesial frontal and anterior temporal areas. In the mesial frontal areas, tracer uptake showed significant reciprocal postoperative changes in shunt-responders compared with nonresponders. The main limitations of this study were the early timing of the postoperative PET study and the lack of MR co-registration.

The issue of anatomical resolution using PET technology was tackled using MR co-registration in a study by Owler et al. ${ }^{58}$ The authors employed $\left[{ }^{15} \mathrm{O}\right] \mathrm{H}_{2} \mathrm{O}$-PET to study global and regional CBF. Regional results were obtained by manually placing small circular regions of interest (ROIs) on relevant structures on the MR image. ROIs were drawn in the following periventricular white matter regions-frontal, occipital, temporal, and parietal regions. ROIs were also placed in the deep gray matter structuresthe thalamus, putamen, and head of the caudate. There was a significant reduction in global CBF results for the cerebrum and cerebellum of NPH patients as compared with the control group. For the regional CBF results in the white matter ROIs, there was no significant difference between the NPH group and controls.

Regional CBF in the deep gray matter structures was, however, significantly reduced in NPH patients as compared with the control group. This PET study was also subject to the limitation that the 2 groups of participants had a significant age difference $(69.6 \pm 9.8$ years for the $\mathrm{NPH}$ group vs $42.8 \pm 9.8$ years for the controls). The findings of significant differences within the thalamus, putamen, and head of the caudate could account for some of the features of gait disturbance in NPH. Disruptions to some of the thalamocortical and frontostriatal pathways would also be in keeping with some of the cognitive deficits in the disease. However, the differences in the blood flow in the cerebellum between NPH patients and controls do not naturally fit with the typical picture of NPH, where there is most likely to be frontal dysexecutive dyspraxia rather than ataxia or dysdiadochokinesis. The differences are thought to be an example of diaschisis (i.e., reduction in frontal $\mathrm{CBF}$ as a primary phenomenon causing a secondary reduction in cerebellar blood flow). The findings cast some doubt over many other PET studies using the cerebellum as a region of reference for analysis on the presumption that this area should be normal.
In parallel to the general findings of reduced global CBF in patients with NPH, other studies have sought to assess the relationship of changes in blood flow to the ventricles. Using $\left[{ }^{15} \mathrm{O}\right] \mathrm{H}_{2} \mathrm{O}$ and image co-registration with 3D structural T1-weighted MRI, Momjian et al. ${ }^{55}$ demonstrated that the percentage change of white matter CBF was in the form of a U-shaped relationship with distance from the ventricles. White matter $\mathrm{CBF}$ was generally reduced in NPH patients, with the maximum reduction adjacent to ventricles and progressive normalization toward the subcortical white matter. The main limitation of this study was the age difference between the NPH patient group (mean age 69 years) and the normal volunteers (mean age 45 years). However, as the main findings were related to the percentage change of white matter $\mathrm{CBF}$ in relation to distance from the ventricles rather than the magnitude of each individual plotted reduction, this limitation is probably acceptable. In the light of the results of this study, it may be possible to explain the variation of periventricular white matter ROI results in PET studies, depending on where the ROIs have been placed on this relationship gradient.

Despite the range of techniques employed in various studies, the main conclusion of reduction in global CBF in $\mathrm{NPH}$ patients as compared with healthy controls remains a fairly consistent finding. However, PET studies are subject to greater technical challenges than other imaging modalities as a result of physiological and psychological factors affecting the acquisition of data. The comparison of follow-up scans may be influenced by variations in study conditions at the time of the scan visit. Advances in resolution and co-registration with other imaging such as MRI may allow more consistent regional blood flow results to be obtained.

Support for the theory of disruption of the thalamocortical and frontostriatal pathways in terms of blood flow can also be found in another study by Tullberg et al.$^{80}$ Using SPECT and ROI analysis, the symptom of impaired wakefulness was investigated in NPH patients undergoing surgical intervention. Reduced relative regional CBF was found in the anterior cingulate cortex of patients with impaired wakefulness. Significant postoperative increases in relative regional CBF were seen in the thalamic, frontal, and hippocampal gray matter regions. Increases in the relative regional blood flow in the frontal association cortex were associated with improvement of the symptom of impaired wakefulness. The limitations of this study were the use of the cerebellum as a region of reference and the poor spatial resolution of SPECT that may adversely affect the precision with which ROI analysis is performed, especially in the context of significant ventriculomegaly. A comprehensive review of $\mathrm{CBF}$ and NPH has been published previously. ${ }^{59}$

\section{CSF Flow}

The presence or absence of a prominent aqueductal CSF flow void has been linked to surgical outcome from shunting. However, the acquisition of these data is highly dependent on the technical characteristics and parameters used in individual MRI systems. Therefore, research in this area has been focused on methods to assess and measure 
the passage of CSF volumes through the aqueduct as a more robust investigative tool. The quantification of CSF flow using MRI has been the subject of several studies, with mixed results. Bradley et al. ${ }^{12}$ calculated CSF stroke volume and aqueductal CSF flow void and compared these parameters with surgical results. Aqueductal stroke volume was defined as the average of the volume of CSF moving craniocaudad during systole and that moving caudocraniad during diastole. These values were derived from measurements on phase-contrast CSF velocity MR images. The authors calculated the aqueductal stroke volume to be the product of the measured velocity of a pixel $(\mathrm{cm} / \mathrm{sec})$ and the area of that pixel $\left(\mathrm{cm}^{2}\right)$ integrated over the crosssectional area of the aqueduct integrated over time over mechanical systole or diastole.

The results demonstrated that all patients with CSF stroke volumes greater than $42 \mu \mathrm{l}$ were shunt-responders. However, half the patients with CSF stroke volumes of 42 $\mu \mathrm{l}$ or less demonstrated improvement with shunting. This suggests that CSF stroke volume has a role as a supplementary test to aid in the selection of patients with NPH who are likely to respond to shunt surgery although the parameter should not be used as an exclusion criterion. The main limitations to this study were the preselection of patients for analysis from the NPH population and the lack of control groups comprising healthy volunteers and patients with other comorbidities. A total of 42 consecutive patients with clinical and supplementary test findings suggestive of NPH underwent imaging during the study period. However, the analysis group comprised 18 patients who underwent surgery, partly based on the results of the CSF flow study as well as the severity of NPH symptomatology and the presence of coexisting disease. As the investigated parameter influenced the selection of patients undergoing surgery, this preselection bias may have positively or negatively influenced the correlation results. The surprisingly large remainder of the patients constituted a group with clinical and supplementary test findings of NPH and thus have already been preselected from a wider group of patients presenting clinically. Therefore, the CSF measurement profiles in the non-shunt-treated group would also be relevant to the NPH spectrum but were not disclosed.

A study by Kahlon et al., ${ }^{39}$ involving a group of 38 patients with suspected NPH, employed cine phase-contrast MRI to assess aqueductal stroke volume. Blinding was maintained with respect to the results until postoperative follow-up after $7 \pm 5.8$ months; patients were then divided into 3 stroke volume groups for analysis-low $(0-50 \mu \mathrm{l})$, middle $(51-100 \mu \mathrm{l})$, and high $(>100 \mu \mathrm{l})$. No correlation was found between statistically significant improvements in clinical outcome assessment and stroke volume in any of the groups. This finding suggests that abnormalities in CSF hydrodynamics alone may not account for all the pathophysiological changes occurring in NPH. Support for a more complicated intracranial hydrodynamic relationship is found in a study by Balédent et al., ${ }^{4}$ who investigated both CSF and CBF in a group of patients with communicating hydrocephalus and a group of healthy volunteers. Patients with communicating hydrocephalus were characterized by hyperdynamic CSF flow through the aq- ueduct. There were no significant differences in cervical CSF oscillations between the 2 groups. However, jugular peak flow was found to occur significantly earlier in patients with communicating hydrocephalus than in controls. This was interpreted as suggesting that venous vessel compression and/or changes in intracranial subarachnoid CSF flow compensate for vascular brain expansion in patients with communicating hydrocephalus, resulting in the increase in ventricular CSF flow.

Bateman and Loiselle ${ }^{7}$ studied a group of 32 patients, including 20 shunt-responders (mean age $74 \pm 7$ years) and 12 nonresponders (mean age $71 \pm 11$ years), using a retrospectively cardiac-gated phase-contrast flow-quantification MRI sequence. This study also included a group of normal elderly volunteers (mean age $70 \pm 5$ years) and patients with Alzheimer's disease (mean age $76 \pm 4$ years). MR flow quantification was performed for the following parameters-degree of ventricular enlargement, sulcal compression, white matter disease, total blood inflow, sagittal sinus outflow, aqueduct stroke volume, relative compliance ratio, and arteriovenous delay. The shunt-responsiveness rate postsurgery was $63 \%$, which is similar to rates reported by many research groups and summarized in the iNPH guidelines. The NPH patient group had significantly increased aqueductal stroke volume as compared with the control group (the authors describe a $210 \%$ increase). The total blood inflow, sagittal sinus outflow, relative compliance ratio, and arteriovenous delay were all significantly reduced in the patient group as compared with controls. The group with Alzheimer's disease exhibited values midway between the NPH and control groups, supporting the need for this group to be considered in parallel to patients with NPH in such studies. Despite the strength of these findings, no significant hydrodynamic parameters distinguished between the shunt-responders and nonresponders. In a more recently published study, Bateman ${ }^{5}$ examined 20 patients with NPH and arterial inflows above the normal range compared with 12 age-matched controls. MRI with flow quantification of total blood inflow, sagittal/straight sinus outflow, aqueduct stroke volume, and arteriovenous delay was performed. The results showed reduced superficial venous outflow and sagittal sinus compliance (arteriovenous delay) and elevated aqueduct stroke volume but normal deep outflow volumes. These findings were interpreted as demonstrating an elevation in superficial venous pressure in NPH.

Conversely, an interesting study by Scollato et al. ${ }^{68}$ examined the stroke volume changes in a group of patients who had clinical and radiological evidence of NPH but refused surgical intervention. Using a phase-contrast cine MRI technique, imaging scans were performed at 6-month intervals for up to 2 years and correlated with symptom progression. This demonstrated that stroke volume was dependent on the time from onset of symptoms, with an increase during the first 18-20 months from the symptom onset, a plateau period, and a decline in the following 18-20 months to a more precipitous drop in the 12 months thereafter. The pattern of this variation suggests that a low stroke volume should not be used as an exclusion criterion for surgery and that these patients may evolve into the group of increased stroke volume more indicative of good 
outcome following surgery. However, a sustained low or declining stroke volume, coupled with clinical deterioration may be a sign of progressive irreversible cerebrovascular ischemic injury that is unlikely to respond to surgical intervention.

Such results have provided the basis for the relative acceptance of CSF flow studies as a supplementary tool for the assessment of shunt-responsive NPH, but the technique remains subject to a variety of challenges in the practical measurement of hyperdynamic flow via the aqueduct. Flow values are likely to be machine specific and vary with alteration of factors ranging from the encoding velocities chosen to balance aliasing versus sensitivity considerations, method of cardiac gating, and automated software for calculation of stroke volume..$^{10,85}$ Patient and pathoanatomical factors also influence such calculations-for example, the amount of atrophy present and correlation of CSF to CBF. This variability may affect the reliability factor of reproducing norms in flow values for individual patients across MR scanners and time points of clinical investigation. Therefore, while the technique is of great relevance to the understanding of pathophysiological processes implicated in NPH, further work is required for standardization and optimization of measures.

It has been suggested that a common pathway leading to the excess accumulation of toxic metabolites may be linked to the evolution of both NPH and Alzheimer's diseases. In this theory, the final subtype of CSF circulatory disorder may hinge upon the predominance of increased resistance to CSF outflow as compared with decreased CSF production and turnover. Failure of drainage of the vasoactive metabolite amyloid- $\beta$ in NPH patients was the subject of an interesting study by Leinonen et al. ${ }^{47}$ Ten patients with mild cognitive impairment and suspected NPH underwent ICP monitoring and concurrent brain biopsy. Frontal cortical specimens were examined using histochemical and immunohistochemical staining for Alzheimer's disease-related pathological lesions. Patients also underwent PET imaging using carbon 11-labeled Pittsburgh Compound B $\left(\left[{ }^{11} \mathrm{C}\right] \mathrm{PiB}\right)$. The authors demonstrated that PET imaging revealed significantly higher $\left[{ }^{11} \mathrm{C}\right] \mathrm{PiB}$ uptake in the frontal, parietal, and lateral temporal cortices and in the striatum of patients with amyloid$\beta$ aggregates in the frontal cortical biopsy specimen than in patients without frontal amyloid- $\beta$ aggregates. In terms of translating these findings to the wider NPH population, the main limitation of the study was the size of the patient group. Of the 125 available patients with suspected NPH who underwent ICP monitoring and cortical biopsy, only 10 patients agreed to participate in the study. The authors did not report the proportion of those patients who ultimately underwent shunt insertion for NPH. Data were not available on the clinical improvement rates following shunt surgery for the institution's typical NPH population. Patients were recruited from the group presenting with suspected NPH, rather than those with a presentation typical of Alzheimer's disease.

Therefore, it is reasonable to suggest that the research participants represented only a small proportion of the NPH-Alzheimer's disease spectrum, and it is unclear whether this preselection bias influenced the findings of the study. Indeed, the study by Silverberg on shunt placement in patients with typical Alzheimer's disease would appear to suggest that drainage of toxic metabolites alone is insufficient to reverse cognitive impairment caused by the presence of amyloid- $\beta$ aggregates. ${ }^{72}$ A much larger study is required to determine whether shunting reduces intracerebral deposition of amyloid- $\beta$ as visualized by $\left[{ }^{11} \mathrm{C}\right] \mathrm{PiB}$. The failure of such treatment theories may also imply that the findings of amyloid- $\beta$ deposits, even within the NPH-Alzheimer's disease spectrum may not be solely responsible for the cognitive impairment seen, thus undermining the usefulness of methods of imaging such aggregates. However, such methods may have a role in aiding in the differential diagnosis of dementia.

\section{Unifying Theories}

Several authors have proposed unifying theories to explain the catalog of results found in NPH. An encephalopathy theory has been proposed by Bateman ${ }^{6}$ based on the induction of pulse waves by the arterial vascular tree on the craniospinal cavity. The theory proposes to incorporate Alzheimer's disease, vascular dementia, and NPH on the basis of a common underlying vascular pathophysiology. In NPH, the proposed mechanism is that elevated arterial pulsations cannot be transmitted to the cortical veins and perivascular spaces due to reduced compliance. The energy from the pulse wave would therefore have to increase the cortical venous outflow pressures by compressing these vessels. This theory does rely on the observation that some studies have shown reduced amounts of CSF expelled from the foramen magnum despite larger arterial pulsations, although this is not a constant finding among studies.

Another interesting hypothesis put forth by Bradley et al. ${ }^{11}$ proposes increased intracranial volumes as the underlying pathology for the development of NPH. The theory suggests that NPH patients have benign external hydrocephalus in infancy, characterized by enlarged ventricles and decreased CSF resorption by immature arachnoid villi. This would lead to significantly larger intracranial volumes than normal in adult life due to these processes occurring prior to fusion of the cranial sutures. Decompensation is then triggered in later life by some insult leading to the development of a symptomatic communicating hydrocephalus (a "two-hit" hypothesis). Various suggestions for the insult that triggers this second stage include deep white matter ischemia, changing viscoelastic properties due to ischemia, and further decreases in CSF resorptive capacity. The authors have also demonstrated significantly larger intracranial volumes in 51 patients with NPH compared with controls $-118 \mathrm{ml}(7.5 \%)$ and $88 \mathrm{ml}(6.3 \%)$ larger in males and females, respectively. These patients were found to have hyperdynamic CSF flow with aqueductal stroke volumes of at least $60 \mu 1,50 \%$ higher than published normal values. ${ }^{13}$

It may not be possible to apply this theory to all cases of NPH, as abnormally raised head circumferences have not been consistently reported in all patients. There is also, conversely, a well-recognized form of subtle aqueduct stenosis with delayed presentation of communicating hy- 
drocephalus within the NPH spectrum. In these patients, suboptimal aqueductal flow leads to larger intracranial volumes due to early expansion of cortical subarachnoid CSF spaces. This subgroup may account for why the application of endoscopic third ventriculostomy has been reported in patients with $\mathrm{NPH} .{ }^{23}$ Despite the difference in underlying etiology, it may well be reasonable to suggest that a second insult also triggers a decompensation in this subgroup, leading to a common end point, i.e., the development of the NPH syndrome. Most of the published evidence suggests that such findings are not applicable to the majority of patients presenting with iNPH. A 2015 Cochrane review reported that the only randomized controlled trial on endoscopic third ventriculostomy versus shunting to meet its criteria for inclusion was unable to determine the effectiveness of the technique due to the use of a nonstandard comparator arm (VP shunting using nonprogrammable valves). ${ }^{78}$ As compared with endoscopic third ventriculostomy, results for VP shunting still appear superior. ${ }^{64,66}$

\section{Diffusion Tensor Imaging-A New Direction?}

In addition to ongoing refinements in the neuroimaging fields highlighted as discussed, the concept of white matter injury in NPH is also being explored (Table 2). Diffusion tensor imaging is able to interrogate tissue microarchitecture and infer patterns of damage across multiple pathologies with relevance to NPH. An early multimodal MR study by Corkill et al. ${ }^{14}$ using diffusion-weighted imaging techniques demonstrated that both normal- and abnormalappearing periventricular tissues exhibited reduced regional cerebral blood volume (rCBV). Despite this finding, rCBV did not change significantly following surgery in either the good or the poor outcome group. Postoperative diffusion-weighted imaging data were not presented due to movement artifact. However, a high ADC in the normal-appearing white matter on preoperative scans was associated with poor outcome following surgery. Areas of white matter hyperintensities were also associated with a high ADC on preoperative scans, suggesting that they represented areas of chronic infarction (i.e., irreversible damage). White matter hyperintensities were found in both symptomatic and asymptomatic individuals. This is consistent with the findings by Tullberg et al. ${ }^{81}$ that deep white matter hyperintensities were not correlated with poor outcome following surgery.

While the use of DTI in NPH is relatively new, evidence from currently available studies suggests that this technique would be a useful and sensitive tool in detecting the white matter microstructural disease in NPH. A study by Ivkovic et al. ${ }^{37}$ demonstrated that it was possible to use DTI as a supplementary test to distinguish NPH from Alzheimer's disease and Parkinson's disease, as well as Lewy body dementia, with a sensitivity of $86 \%$ and specificity of $96 \%$. This was confirmed by Hattori et al., ${ }^{34}$ who demonstrated that alterations in corticospinal tract microstructure were sufficient to discriminate NPH from Alzheimer's and Parkinson's diseases with a sensitivity of $94 \%$ and specificity of $80 \%$. It is promising to note that DTI is sufficiently sensitive to demonstrate decreases in mean diffusivities even with external lumbar drainage. ${ }^{38}$ However, the relative importance of individual DTI measures with respect to the interpretation of responsiveness to CSF drainage remains a matter for debate. What is lacking is cohesiveness of visualization and quantification of DTI analysis to complement the variability in the NPH clinical spectrum. ${ }^{8,24,33,40}$ A DTI interpretation method that is transparent-able to distinguish different coexisting pathological processes-would be highly advantageous. This would allow for fair assessment of risk for progression as well as responsiveness to intervention. By using concurrent examination of diffusion measures to reveal DTI profiles and correlating them with plots of isotropy (P) versus anisotropy $(\mathrm{Q})$, our group has found that it is possible to characterize different white matter injury patterns within NPH. Early work suggests different degrees of responsiveness to surgical intervention for different injury patterns. We found significant decreases in axial diffusivity in the posterior limb of the internal capsule as early as 2 weeks after shunting, with further decreases at 6 months, compatible with improvement of the pattern of stretch/compression (Keong et al., in submission). ${ }^{41}$ Further work is needed to correlate these and other findings to clinical outcome groups.

White matter changes occurring in purer forms of hydrocephalus, such as pediatric and obstructive subtypes, have also been described using DTI. ${ }^{3,8,48,82,86}$ Yet, the complex pathophysiological sequencing of NPH remains uncertain; DTI interpretation may allow the appreciation of injury without presupposing knowledge of predominant mechanisms of injury. As differing pathologies-ranging from structural degradation to compression and axonal swelling - can be distinguished using the analysis of individual DTI measures, it is an ideal investigative tool for $\mathrm{NPH}$ where the different processes may be occurring in parallel in different white matter sections, or in relation to its temporal evolution. The lessons learned from different pathologies, from focal to diffuse, may therefore be extremely valuable in translating this tool to NPH. Interpretation of DTI measures across a range of pathological conditions, such as demyelination, acute traumatic brain injury, dementia, and ischemia, may be applicable to the white matter injury patterns in NPH, particularly due to the fact that the underlying pathological mechanisms in this condition have not been fully elucidated (see Table 3 for a summary of key concepts and conundrums). To this end, the concept of imaging reversible white matter injury may lead to the next leap in the understanding of the enigma known as the "syndrome of treatable occult hydrocephalus."

\section{Conclusions}

Although decades have passed since the initial conceptualization of NPH, the underlying theories of its pathogenesis still continue to provoke debate. These theories may not be mutually exclusive. The differential diagnoses within the NPH spectrum, such as Binswanger's, Parkinson's, and Alzheimer's diseases, may overlap, leading to the concept of a "remediable" component to CSF diversion existing within the spectrum. Many questions remain 
TABLE 2. Summary of relevant literature on DTI related to pathophysiological theories in NPH

\begin{tabular}{|c|c|c|c|c|}
\hline $\begin{array}{l}\text { Authors } \\
\& \text { Year }\end{array}$ & Pathology & Method & Cases & Key Findings \\
\hline $\begin{array}{l}\text { Gideon } \\
\text { et al., } \\
1994\end{array}$ & $\mathrm{HC}$ & $\begin{array}{l}\text { MR diffu- } \\
\text { sion }\end{array}$ & $5 \mathrm{NPH}, 2 \mathrm{HPH}$ & $\begin{array}{l}\text { In NPH, sig elevations of ADC of brain water in periventricular WM, corpus callosum, internal cap- } \\
\text { sule, cortical gray matter; normal ADCs in basal ganglia. In HPH, elevated ADCs found most } \\
\text { prominently in WM. Increased ADC in HC postulated to be caused by changes in myelin-asso- } \\
\text { ciated bound water, increased Virchow-Robin spaces, \& } \uparrow \text { extracellular brain water fraction. }\end{array}$ \\
\hline $\begin{array}{l}\text { Uluğ et } \\
\quad \text { al., } \\
2003\end{array}$ & $\mathrm{OH}$ & $\begin{array}{l}\text { MR dif- } \\
\text { fusion } \\
\text { imaging }\end{array}$ & $21 \mathrm{OH}$ & $\begin{array}{l}D(\text { av) in periventricular WM measured before \& after treatment \& compared w/ normal values. } \\
D(a v) \uparrow \text { in periventricular WM of CH pts compared w/ age-matched controls. Posttreatment, } \\
D(a v) \downarrow \text { in } 53 \% \text { of pts (11/21), remained unchanged in } 33 \%(7 / 21), \& \uparrow \text { in } 14 \%(3 / 21) \text {. }\end{array}$ \\
\hline $\begin{array}{l}\text { Corkill } \\
\text { et al., } \\
2003\end{array}$ & $\mathrm{NPH}$ & $\begin{array}{l}\text { Multi- } \\
\text { modal } \\
\text { MRI }\end{array}$ & $\begin{array}{c}11 \mathrm{NPH}(+10 \\
\quad H V s)\end{array}$ & $\begin{array}{l}\text { Preop periventricular rCBV } \downarrow \text { in pts compared to controls. rCBV did not change significantly either } \\
\text { in the good or poor outcome groups. No postop diffusion data presented due to movement } \\
\text { artifact. Preop changes: normal-appearing periventricular tissue }=\downarrow \text { rCBV; } \uparrow A D C \text { correlated } \\
\text { w/ poor outcome group following surgery. WMH } \downarrow \text { rCBV, } \uparrow \text { in ADC }=\text { chronic infarction or ir- } \\
\text { reversible damage? WMH in both symptomatic \& asymptomatic pts. }\end{array}$ \\
\hline $\begin{array}{l}\text { Assaf } \\
\text { et al., } \\
2006\end{array}$ & $\mathrm{HC}$ & DTI & $7 \mathrm{CH}(+8 \mathrm{HVs})$ & $\begin{array}{l}\text { Pediatric participants only: FA } \uparrow \text { lateral to ventricles, e.g., } C R(\uparrow \text { parallel diffusivity } \& \downarrow \text { radial diffu- } \\
\text { sivity). In } 6 \text { of } 7 \text { pts, FA values approached HV values postoperatively. FA } \downarrow \text { in corpus callosum } \\
\text { preop; no sig postop change. }\end{array}$ \\
\hline $\begin{array}{l}\text { Yuan et } \\
\text { al., } \\
2009\end{array}$ & $\mathrm{HC}$ & DTI & $17 \mathrm{CH}$ (17 HVs) & $\begin{array}{l}\text { Infants diagnosed w/ HC: significantly lower FA, higher MD, \& higher radial diffusivity values for all } \\
3 \text { ROls in corpus callosum but not for the } 2 \text { ROls in internal capsule. In HC, FA } \uparrow \text { w/ age during } \\
\text { normal development was absent in corpus callosum but still preserved in internal capsule. }\end{array}$ \\
\hline $\begin{array}{l}\text { Leliefeld } \\
\text { et al., } \\
2009\end{array}$ & $\mathrm{HC}$ & $\begin{array}{l}\text { MR dif- } \\
\text { fusion } \\
\text { imaging }\end{array}$ & $24 \mathrm{CH}$ & $\begin{array}{l}\text { Preop ADC values were higher than age-based normal values \& postop ADC values were lower. } \\
\text { Preop ICP was elevated in all pts. The decrease in ADC values after CSF diversion was more } \\
\text { rapid \& extensive than to be expected from physiological ADC decrease solely due to increas- } \\
\text { ing patient age. }\end{array}$ \\
\hline $\begin{array}{l}\text { Kanno } \\
\text { et al., } \\
2011\end{array}$ & NPH & DTI & $\begin{array}{r}20 \text { iNPH, } 20 \\
\text { AD, } 20 \text { PD }\end{array}$ & $\begin{array}{l}\text { Supratentorial WM presented higher MD \& lower FA in iNPH group compared to controls. WM re- } \\
\text { gions w/ high MD (periventricular regions) were not related to Sx manifestation. Low FA regions } \\
\text { (corpus callosum \& subcortical regions) were related to motor \& cognitive dysfunction in iNPH. }\end{array}$ \\
\hline $\begin{array}{l}\text { Hattori } \\
\text { et al., } \\
2011\end{array}$ & $\mathrm{NPH}$ & DTI & $\begin{array}{l}18 \mathrm{NPH}, 11 \mathrm{AD}, \\
11 \mathrm{PD} \text { w/ } \\
\text { dementia, (+ } \\
19 \mathrm{HVs})\end{array}$ & $\begin{array}{l}\text { Analysis of CST showed that FA values \& axial eigenvalues were significantly } \uparrow(p<0.001) \& \\
\text { radial eigenvalues were not significantly altered in pts w/ iNPH compared to other subjects. } \\
\text { CST tractographic images were visually different }(p<0.001) \text { in pts w/ iNPH compared to other } \\
\text { subjects. CST FA values had sensitivity of } 94 \% \text { specificity of } 80 \% \text { at a cutoff value of } 0.59 \text { in } \\
\text { discriminating pts w/ iNPH from other subjects. }\end{array}$ \\
\hline $\begin{array}{l}\text { Hattori } \\
\text { et al., } \\
2012\end{array}$ & $\mathrm{NPH}$ & DTI & $\begin{array}{c}20 \mathrm{NPH}(+20 \\
\text { HVs) }\end{array}$ & $\begin{array}{l}\text { TBSS analysis showed FA values were significantly } \downarrow \text { in pts compared w/ controls in parts of the } \\
\text { corpus callosum periventricular WM \& juxtacortical WM in frontal \& parietal lobes. FA values } \\
\text { were significantly } \uparrow \text { in internal capsule, extending to WM in centrum semiovale. }\end{array}$ \\
\hline $\begin{array}{l}\text { Ivkovic } \\
\text { et al., } \\
2013\end{array}$ & NPH & DTI & $\begin{array}{l}15 \mathrm{NPH}, 25 \mathrm{AD}, \\
\text { PD/dementia } \\
\quad+\text { LB }\end{array}$ & $\begin{array}{l}\text { Parametric model for shape of intracranial MD histograms. MD histogram analysis distinguished } \\
\text { clinically probable NPH from the } 3 \text { other disorders w/ } 86 \% \text { sensitivity \& } 96 \% \text { specificity; } 86 \% \\
\text { sensitivity \& } 88 \% \text { specificity when differentiating NPH from AD only. }\end{array}$ \\
\hline $\begin{array}{l}\text { Ivkovic } \\
\text { et al., } \\
2015\end{array}$ & $\mathrm{NPH}$ & $\begin{array}{l}\text { DTI } \\
\text { ASL }\end{array}$ & $25 \mathrm{iNPH}$ & $\begin{array}{l}\text { 8/25 pts had acetazolamide ( } 3 \text { mos), } 12 / 25 \text { underwent external lumbar drainage (up to } 72 \text { hrs), } \\
5 / 25 \text { serially scanned as controls. } \downarrow \text { vol of T1 hypointensities } \& \downarrow \text { MD w/in remaining hypoin- } \\
\text { tensities were observed after acetazolamide \& external lumbar drainage but not in controls. } \\
\text { Magnitude of decrease was greater in treatment responders than nonresponders. Both inter- } \\
\text { ventions are postulated to decrease interstitial brain water \& increase CBF in iNPH. }\end{array}$ \\
\hline $\begin{array}{l}\text { Ben-sira } \\
\text { et al., } \\
2015\end{array}$ & $\mathrm{HC}$ & DTI & $35 \mathrm{HC}$ & $\begin{array}{l}\text { DTI values of pts compared w/ values extracted from age-dependent trend lines computed from } \\
\text { a healthy subject group }(n=70) \text {. Pts w/ HC had statistically sig changes in all DTI parameters. } \\
\text { The most sensitive \& specific DTI parameter for predicting HC was axial diffusivity at the CR. }\end{array}$ \\
\hline
\end{tabular}

$\mathrm{ACR}=$ anterior corona radiata; $\mathrm{ADC}=$ apparent diffusion coefficient; $\mathrm{ASL}=$ arterial spin labeling; $\mathrm{CR}=$ corona radiata; $\mathrm{CST}=$ corticospinal tract; $\mathrm{D}(\mathrm{av})=\mathrm{average}$ diffusion constant; $F A=$ fractional anisotropy; $\mathrm{GCC}=$ genu of the corpus callosum; $\mathrm{HC}=$ hydrocephalus; $\mathrm{HPH}=$ high pressure hydrocephalus; ILF = inferior longitudinal fasciculus; $\mathrm{LB}=$ Lewy bodies; $\mathrm{MCl}$ = mild cognitive impairment; $\mathrm{MD}=$ mean diffusivity; $\mathrm{NAWM}=$ normal-appearing white matter; $\mathrm{OH}=$ obstructive hydrocephalus; $\mathrm{PD}$ = Parkinson's disease; TBSS $=$ tract-based spatial statistics; UNC = uncinate fasciculus.

about the fundamental contributions of diverse pathophysiological processes to the development and evolution of this fascinating condition. It is likely that the key to grappling with the complexities in NPH lies in the ability to correlate multiple neuroimaging and clinical biomarker strands into an integrated risk stratification framework. Further work on NPH is imperative; few conditions in the elderly are associated with such responsiveness to therapy. Understanding the nature of reversibility of brain injury in NPH may lead, not only to improved interventions in this 
TABLE 3. Summary of key concepts and conundrums relevant to the pathophysiological theories of NPH

\begin{tabular}{|c|c|c|}
\hline Key Theory Streams & Key Concepts & Imaging Concepts \& Conundrums \\
\hline $\begin{array}{l}\text { Structural: tissue } \\
\text { distortion \& } \\
\text { biomechanical, } \\
\text { interstitial fluid } \\
\text { pressure increase }\end{array}$ & $\begin{array}{l}\text { Tissue distortion secondary to raised intraventricular pres- } \\
\text { sure. } \\
\text { Disruption of periventricular tissue, parenchyma, \& vessels, } \\
\text { either by compression or by stretching. } \\
\text { Loss of elasticity \& ischemia. } \\
\text { Reversal of pressure gradient at mantle. } \\
\text { Reversal of interstitial fluid flow = edema. } \\
\text { Failure of drainage of vasoactive metabolites = accumulation } \\
\text { of } A \beta \text { peptides \& tau protein. }\end{array}$ & $\begin{array}{l}\text { Stresses leading to brain deformation \& geometry of ventricular } \\
\text { expansion have been modeled by finite imaging analysis. } \\
\text { Evidence from MR elastography \& animal studies of alteration } \\
\text { of viscoelastic properties of brain tissue \& disturbance of } \\
\text { periventricular matrix integrity favoring progressive ventricu- } \\
\text { lomegaly. } \\
\text { Transmantle gradients have never been documented. } \\
\text { Pulse waveform in CSF recordings appears to be slightly } \\
\text { greater (but not always) than in the parenchyma (see Fig. 2). }\end{array}$ \\
\hline $\begin{array}{l}\text { CBF: watershed } \\
\text { ischemia, vascu- } \\
\text { lar disease }\end{array}$ & $\begin{array}{l}\text { Ventricular expansion distorts connections \&/or blood ves- } \\
\text { sels btwn basal ganglia \& frontal cortex. } \\
\text { Stretching of blood vessels causing deep lacunar infarctions. } \\
\text { Dysfunctional regional cerebral autoregulation \& watershed } \\
\text { ischemia. } \\
\text { Infarctions may be the cause of loss of elasticity, allowing } \\
\text { progressive ventricular expansion. }\end{array}$ & $\begin{array}{l}\text { Overlapping vascular diseases w/ CSF disorder have been } \\
\text { studied, but cohorts may represent different ends of the spec- } \\
\text { trum: pts w/ } \uparrow \text { Rcsf had more frequently normal autoregula- } \\
\text { tion of CBF \& those w/ normal CSF circulation had more } \\
\text { frequently disturbed autoregulation. } \\
\text { However, static rate of autoregulation in WM did demonstrate a } \\
\text { relationship to distance from ventricles in NPH (see Fig. 3). }\end{array}$ \\
\hline $\begin{array}{l}\text { CSF flow: CSF } \\
\text { hydrodynamics, } \\
\text { failure of drainage } \\
\text { of vasoactive } \\
\text { substances }\end{array}$ & $\begin{array}{l}\text { Adult CH: other causes should be excluded. } \\
\text { CSF circulatory disorder, involving an imbalance btwn CSF } \\
\quad \text { production \& reabsorption. } \\
\uparrow \text { Rcsf. } \\
\uparrow \text { amplitude of ICP pulse waveform. } \\
\text { Progressive brain parenchymal stiffness. } \\
\downarrow \text { CSF production \& turnover. } \\
\text { Inability to clear toxic metabolic products. }\end{array}$ & $\begin{array}{l}\text { Variability in published ranges of sensitivity \& specificity of } \\
\text { supplementary testing involving CSF drainage \& correlation } \\
\text { w/ differing NPH scores. } \\
\text { Technical challenges affecting reliability of MR-based CSF flow } \\
\text { studies in generating values for norms. } \\
\uparrow \text { Rcsf during infusion testing implicated as a factor for develop- } \\
\text { ment of HC challenged in recent studies; no apparent correla- } \\
\text { tion btwn degree of ventricular dilation \& magnitude of pulse } \\
\text { amplitude measured. }\end{array}$ \\
\hline
\end{tabular}

field, but also to wider implications for conditions of acuteon-chronic injury as a whole.

\section{References}

1. Akai K, Uchigasaki S, Tanaka U, Komatsu A: Normal pressure hydrocephalus. Neuropathological study. Acta Pathol Jpn 37:97-110, 1987

2. Akiguchi I, Ishii M, Watanabe Y, Watanabe T, Kawasaki T, Yagi $\mathrm{H}$, et al: Shunt-responsive parkinsonism and reversible white matter lesions in patients with idiopathic NPH. J Neurol 255:1392-1399, 2008

3. Assaf Y, Ben-Sira L, Constantini S, Chang LC, Beni-Adani L: Diffusion tensor imaging in hydrocephalus: initial experience. AJNR Am J Neuroradiol 27:1717-1724, 2006

4. Balédent O, Gondry-Jouet C, Meyer ME, De Marco G, Le Gars D, Henry-Feugeas MC, et al: Relationship between cerebrospinal fluid and blood dynamics in healthy volunteers and patients with communicating hydrocephalus. Invest Radiol 39:45-55, 2004

5. Bateman GA: The pathophysiology of idiopathic normal pressure hydrocephalus: cerebral ischemia or altered venous hemodynamics? AJNR Am J Neuroradiol 29:198-203, 2008

6. Bateman GA: Pulse wave encephalopathy: a spectrum hypothesis incorporating Alzheimer's disease, vascular dementia and normal pressure hydrocephalus. Med Hypotheses 62:182-187, 2004

7. Bateman GA, Loiselle AM: Can MR measurement of intracranial hydrodynamics and compliance differentiate which patient with idiopathic normal pressure hydrocephalus will improve following shunt insertion? Acta Neurochir (Wien) 149:455-462, 2007
8. Ben-Sira L, Goder N, Bassan H, Lifshits S, Assaf Y, Constantini S: Clinical benefits of diffusion tensor imaging in hydrocephalus. J Neurosurg Pediatr 16:195-202, 2015

9. Børgesen SE, Gjerris F: The predictive value of conductance to outflow of CSF in normal pressure hydrocephalus. Brain 105:65-86, 1982

10. Bradley WG Jr: CSF flow in the brain in the context of normal pressure hydrocephalus. AJNR Am J Neuroradiol 36:831-838, 2015

11. Bradley WG Jr, Bahl G, Alksne JF: Idiopathic normal pressure hydrocephalus may be a "two hit" disease: benign external hydrocephalus in infancy followed by deep white matter ischemia in late adulthood. J Magn Reson Imaging 24:747-755, 2006

12. Bradley WG Jr, Scalzo D, Queralt J, Nitz WN, Atkinson DJ, Wong P: Normal-pressure hydrocephalus: evaluation with cerebrospinal fluid flow measurements at MR imaging. Radiology 198:523-529, 1996

13. Bradley WG, Safar FG, Furtado C, Ord J, Alksne JF: Increased intracranial volume: a clue to the etiology of idiopathic normal-pressure hydrocephalus? AJNR Am J Neuroradiol 25:1479-1484, 2004 (Erratum in AJNR Am J Neuroradiol 26:203, 2005)

14. Corkill RG, Garnett MR, Blamire AM, Rajagopalan B, Cadoux-Hudson TA, Styles P: Multi-modal MRI in normal pressure hydrocephalus identifies pre-operative haemodynamic and diffusion coefficient changes in normal appearing white matter correlating with surgical outcome. Clin Neurol Neurosurg 105:193-202, 2003

15. Czosnyka M, Czosnyka ZH, Whitfield PC, Donovan T, Pickard JD: Age dependence of cerebrospinal pressure-volume compensation in patients with hydrocephalus. J Neurosurg 94:482-486, 2001

16. Czosnyka ZH, Czosnyka M, Whitfield PC, Donovan T, Pick- 
ard JD: Cerebral autoregulation among patients with symptoms of hydrocephalus. Neurosurgery 50:526-533, 2002

17. DeVito EE, Salmond CH, Owler BK, Sahakian BJ, Pickard JD: Caudate structural abnormalities in idiopathic normal pressure hydrocephalus. Acta Neurol Scand 116:328-332, 2007

18. Earnest MP, Fahn S, Karp JH, Rowland LP: Normal pressure hydrocephalus and hypertensive cerebrovascular disease. Arch Neurol 31:262-266, 1974

19. Eide PK, Brean A: Intracranial pulse pressure amplitude levels determined during preoperative assessment of subjects with possible idiopathic normal pressure hydrocephalus. Acta Neurochir (Wien) 148:1151-1156, 2006

20. Factora R: When do common symptoms indicate normal pressure hydrocephalus? Cleve Clin J Med 73:447-450, 452, 455-446, 2006

21. Fisher CM: Lacunar strokes and infarcts: a review. Neurology 32:871-876, 1982

22. Freimann FB, Streitberger KJ, Klatt D, Lin K, McLaughlin J, Braun J, et al: Alteration of brain viscoelasticity after shunt treatment in normal pressure hydrocephalus. Neuroradiology 54:189-196, 2012

23. Gangemi M, Maiuri F, Buonamassa S, Colella G, de Divitiis E: Endoscopic third ventriculostomy in idiopathic normal pressure hydrocephalus. Neurosurgery 55:129-134, 2004

24. Gideon P, Thomsen C, Gjerris F, Sørensen PS, Henriksen $\mathrm{O}$ : Increased self-diffusion of brain water in hydrocephalus measured by MR imaging. Acta Radiol 35:514-519, 1994

25. Godersky JC, Graff-Radford NR, Yuh WT: Magnetic resonance imaging of patients with normal pressure hydrocephalus. Adv Neurol 52:554, 1990

26. Graff-Radford NR, Godersky JC: Idiopathic normal pressure hydrocephalus and systemic hypertension. Neurology 37:868-871, 1987

27. Greitz T: Effect of brain distension on cerebral circulation. Lancet 1:863-865, 1969

28. Haan J, Thomeer RT: Predictive value of temporary external lumbar drainage in normal pressure hydrocephalus. Neurosurgery 22:388-391, 1988

29. Hakim S, Adams RD: The special clinical problem of symptomatic hydrocephalus with normal cerebrospinal fluid pressure. Observations on cerebrospinal fluid hydrodynamics. J Neurol Sci 2:307-327, 1965

30. Hakim S, Venegas JG, Burton JD: The physics of the cranial cavity, hydrocephalus and normal pressure hydrocephalus: mechanical interpretation and mathematical model. Surg Neurol 5:187-210, 1976

31. Halperin JJ, Kurlan R, Schwalb JM, Cusimano MD, Gronseth G, Gloss D: Practice guideline: Idiopathic normal pressure hydrocephalus: Response to shunting and predictors of response: Report of the Guideline Development, Dissemination, and Implementation Subcommittee of the American Academy of Neurology. Neurology 85:2063-2071, 2015

32. Hashimoto M, Ishikawa M, Mori E, Kuwana N: Diagnosis of idiopathic normal pressure hydrocephalus is supported by MRI-based scheme: a prospective cohort study. Cerebrospinal Fluid Res 7:18, 2010

33. Hattori T, Ito K, Aoki S, Yuasa T, Sato R, Ishikawa M, et al: White matter alteration in idiopathic normal pressure hydrocephalus: tract-based spatial statistics study. AJNR Am J Neuroradiol 33:97-103, 2012

34. Hattori T, Yuasa T, Aoki S, Sato R, Sawaura H, Mori T, et al: Altered microstructure in corticospinal tract in idiopathic normal pressure hydrocephalus: comparison with Alzheimer disease and Parkinson disease with dementia. AJNR Am J Neuroradiol 32:1681-1687, 2011

35. Holodny AI, Waxman R, George AE, Rusinek H, Kalnin AJ, de Leon M: MR differential diagnosis of normal-pressure hydrocephalus and Alzheimer disease: significance of perihip- pocampal fissures. AJNR Am J Neuroradiol 19:813-819, 1998

36. Ishikawa M, Hashimoto M, Mori E, Kuwana N, Kazui H: The value of the cerebrospinal fluid tap test for predicting shunt effectiveness in idiopathic normal pressure hydrocephalus. Fluids Barriers CNS 9:1, 2012

37. Ivkovic M, Liu B, Ahmed F, Moore D, Huang C, Raj A, et al: Differential diagnosis of normal pressure hydrocephalus by MRI mean diffusivity histogram analysis. AJNR Am J Neuroradiol 34:1168-1174, 2013

38. Ivkovic M, Reiss-Zimmermann M, Katzen H, Preuss M, Kovanlikaya I, Heier L, et al: MRI assessment of the effects of acetazolamide and external lumbar drainage in idiopathic normal pressure hydrocephalus. Fluids Barriers CNS 12:9, 2015

39. Kahlon B, Annertz M, Ståhlberg F, Rehncrona S: Is aqueductal stroke volume, measured with cine phase-contrast magnetic resonance imaging scans useful in predicting outcome of shunt surgery in suspected normal pressure hydrocephalus? Neurosurgery 60:124-130, 2007

40. Kanno S, Abe N, Saito M, Takagi M, Nishio Y, Hayashi A, et al: White matter involvement in idiopathic normal pressure hydrocephalus: a voxel-based diffusion tensor imaging study. J Neurol 258:1949-1957, 2011

41. Keong N, Pena A, Price S, Czosnyka M, Czosnyka Z, DeVito E, et al: Profiling patterns of white matter injury in normal pressure hydrocephalus pre- and post-intervention using diffusion tensor imaging, in International Society for Magnetic Resonance in Medicine 24th Annual Meeting and Exhibition. Singapore: ISMRM, 2016 (Poster) (http://www. ismrm.org/16/program_files/TP01.htm) [Accessed July 20, 2016 ]

42. Kimura M, Tanaka A, Yoshinaga S: Significance of periventricular hemodynamics in normal pressure hydrocephalus. Neurosurgery 30:701-705, 1992

43. Kitagaki H, Mori E, Ishii K, Yamaji S, Hirono N, Imamura $\mathrm{T}$ : CSF spaces in idiopathic normal pressure hydrocephalus: morphology and volumetry. AJNR Am J Neuroradiol 19:1277-1284, 1998

44. Klinge PM, Berding G, Brinker T, Knapp WH, Samii M: A positron emission tomography study of cerebrovascular reserve before and after shunt surgery in patients with idiopathic chronic hydrocephalus. J Neurosurg 91:605-609, 1999

45. Klinge PM, Brooks DJ, Samii A, Weckesser E, van den Hoff J, Fricke H, et al: Correlates of local cerebral blood flow $(\mathrm{CBF})$ in normal pressure hydrocephalus patients before and after shunting-a retrospective analysis of $\left[{ }^{15} \mathrm{O}\right] \mathrm{H}_{2} \mathrm{O}$ PET-CBF studies in 65 patients. Clin Neurol Neurosurg 110:369-375, 2008

46. Krauss JK, Droste DW, Vach W, Regel JP, Orszagh M, Borremans JJ, et al: Cerebrospinal fluid shunting in idiopathic normal-pressure hydrocephalus of the elderly: effect of periventricular and deep white matter lesions. Neurosurgery 39:292-300, 1996

47. Leinonen V, Alafuzoff I, Aalto S, Suotunen T, Savolainen S, Någren K, et al: Assessment of beta-amyloid in a frontal cortical brain biopsy specimen and by positron emission tomography with carbon 11-labeled Pittsburgh Compound B. Arch Neurol 65:1304-1309, 2008

48. Leliefeld PH, Gooskens RH, Braun KP, Ramos LM, Uiterwaal CS, Regli LP, et al: Longitudinal diffusion-weighted imaging in infants with hydrocephalus: decrease in tissue water diffusion after cerebrospinal fluid diversion. J Neurosurg Pediatr 4:56-63, 2009

49. Malm J, Kristensen B, Karlsson T, Fagerlund M, Elfverson J, Ekstedt J: The predictive value of cerebrospinal fluid dynamic tests in patients with the idiopathic adult hydrocephalus syndrome. Arch Neurol 52:783-789, 1995

50. Marmarou A, Bergsneider M, Klinge P, Relkin N, Black PM: 
The value of supplemental prognostic tests for the preoperative assessment of idiopathic normal-pressure hydrocephalus. Neurosurgery 57 (3 Suppl):S17-S28, ii-v, 2005

51. Marmarou A, Takagi H, Shulman K: Biomechanics of brain edema and effects on local cerebral blood flow. Adv Neurol 28:345-358, 1980

52. Mathew NT, Meyer JS, Hartmann A, Ott EO: Abnormal cerebrospinal fluid-blood flow dynamics. Implications in diagnosis, treatment, and prognosis in normal pressure hydrocephalus. Arch Neurol 32:657-664, 1975

53. Meltzer CC, Cantwell MN, Greer PJ, Ben-Eliezer D, Smith G, Frank G, et al: Does cerebral blood flow decline in healthy aging? A PET study with partial-volume correction. J Nucl Med 41:1842-1848, 2000

54. Meyer JS, Tachibana H, Hardenberg JP, Dowell RE Jr, Kitagawa Y, Mortel KF: Normal pressure hydrocephalus. Influences on cerebral hemodynamic and cerebrospinal fluid pressurechemical autoregulation. Surg Neurol 21:195-203, 1984

55. Momjian S, Owler BK, Czosnyka Z, Czosnyka M, Pena A, Pickard JD: Pattern of white matter regional cerebral blood flow and autoregulation in normal pressure hydrocephalus. Brain 127:965-972, 2004

56. Nagra G, Koh L, Aubert I, Kim M, Johnston M: Intraventricular injection of antibodies to beta1-integrins generates pressure gradients in the brain favoring hydrocephalus development in rats. Am J Physiol Regul Integr Comp Physiol 297:R1312-R1321, 2009

57. Owler BK, Momjian S, Czosnyka Z, Czosnyka M, Péna A, Harris NG, et al: Normal pressure hydrocephalus and cerebral blood flow: a PET study of baseline values. J Cereb Blood Flow Metab 24:17-23, 2004

58. Owler BK, Pena A, Momjian S, Czosnyka Z, Czosnyka M, Harris NG, et al: Changes in cerebral blood flow during cerebrospinal fluid pressure manipulation in patients with normal pressure hydrocephalus: a methodological study. J Cereb Blood Flow Metab 24:579-587, 2004

59. Owler BK, Pickard JD: Normal pressure hydrocephalus and cerebral blood flow: a review. Acta Neurol Scand 104:325342, 2001

60. Palm WM, Walchenbach R, Bruinsma B, Admiraal-Behloul F, Middelkoop HA, Launer LJ, et al: Intracranial compartment volumes in normal pressure hydrocephalus: volumetric assessment versus outcome. AJNR Am J Neuroradiol 27:76-79, 2006

61. Peña A, Bolton MD, Whitehouse H, Pickard JD: Effects of brain ventricular shape on periventricular biomechanics: a finite-element analysis. Neurosurgery 45:107-118, 1999

62. Peña A, Harris NG, Bolton MD, Czosnyka M, Pickard JD: Communicating hydrocephalus: the biomechanics of progressive ventricular enlargement revisited. Acta Neurochir Suppl 81:59-63, 2002

63. Pickard JD: Adult communicating hydrocephalus. Br J Hosp Med 27:35, 37-38, 40, 1982

64. Pinto FC, Saad F, Oliveira MF, Pereira RM, Miranda FL, Tornai JB, et al: Role of endoscopic third ventriculostomy and ventriculoperitoneal shunt in idiopathic normal pressure hydrocephalus: preliminary results of a randomized clinical trial. Neurosurgery 72:845-854, 2013

65. Relkin N, Marmarou A, Klinge P, Bergsneider M, Black PM: Diagnosing idiopathic normal-pressure hydrocephalus. Neurosurgery 57 (3 Suppl):S4-S16, ii-v, 2005

66. Sankey EW, Jusué-Torres I, Elder BD, Goodwin CR, Batra S, Hoffberger J, et al: Functional gait outcomes for idiopathic normal pressure hydrocephalus after primary endoscopic third ventriculostomy. J Clin Neurosci 22:1303-1308, 2015

67. Sasaki M, Honda S, Yuasa T, Iwamura A, Shibata E, Ohba H: Narrow CSF space at high convexity and high midline areas in idiopathic normal pressure hydrocephalus detected by axial and coronal MRI. Neuroradiology 50:117-122, 2008
68. Scollato A, Tenenbaum R, Bahl G, Celerini M, Salani B, Di Lorenzo N: Changes in aqueductal CSF stroke volume and progression of symptoms in patients with unshunted idiopathic normal pressure hydrocephalus. AJNR Am J Neuroradiol 29:192-197, 2008

69. Shulman KMA, Weitz S: Gradients of brain interstitial fluid pressure in experimental brain infusion and compression, in Lundberg N, Ponten U, Kasner M (eds): Intracranial Pressure II. Berlin: Springer, 1975, pp 221-223

70. Silverberg G, Mayo M, Saul T, Fellmann J, McGuire D: Elevated cerebrospinal fluid pressure in patients with Alzheimer's disease. Cerebrospinal Fluid Res 3:7, 2006

71. Silverberg GD: Normal pressure hydrocephalus (NPH): ischaemia, CSF stagnation or both. Brain 127:947-948, 2004

72. Silverberg GD, Mayo M, Saul T, Fellmann J, Carvalho J, McGuire D: Continuous CSF drainage in AD: results of a double-blind, randomized, placebo-controlled study. Neurology 71:202-209, 2008

73. Silverberg GD, Mayo M, Saul T, Rubenstein E, McGuire D: Alzheimer's disease, normal-pressure hydrocephalus, and senescent changes in CSF circulatory physiology: a hypothesis. Lancet Neurol 2:506-511, 2003

74. Streitberger KJ, Wiener E, Hoffmann J, Freimann FB, Klatt $\mathrm{D}$, Braun J, et al: In vivo viscoelastic properties of the brain in normal pressure hydrocephalus. NMR Biomed 24:385392,2011

75. Tamaki N, Nagashima T, Ehara K, Shirakuni T, Matsumoto $\mathrm{S}$ : Hydrocephalic oedema in normal-pressure hydrocephalus. Acta Neurochir Suppl 51:348-350, 1990

76. Tanaka A, Kimura M, Nakayama Y, Yoshinaga S, Tomonaga M: Cerebral blood flow and autoregulation in normal pressure hydrocephalus. Neurosurgery 40:1161-1167, 1997

77. Tedeschi E, Hasselbalch SG, Waldemar G, Juhler M, Høgh P, Holm S, et al: Heterogeneous cerebral glucose metabolism in normal pressure hydrocephalus. J Neurol Neurosurg Psychiatry 59:608-615, 1995

78. Tudor KI, Tudor M, McCleery J, Car J: Endoscopic third ventriculostomy (ETV) for idiopathic normal pressure hydrocephalus (iNPH). Cochrane Database Syst Rev (7):CD010033, 2015

79. Tullberg M, Blennow K, Månsson JE, Fredman P, Tisell M, Wikkelsö C: Ventricular cerebrospinal fluid neurofilament protein levels decrease in parallel with white matter pathology after shunt surgery in normal pressure hydrocephalus. Eur J Neurol 14:248-254, 2007

80. Tullberg M, Hellström P, Piechnik SK, Starmark JE, Wikkelsö C: Impaired wakefulness is associated with reduced anterior cingulate $\mathrm{CBF}$ in patients with normal pressure hydrocephalus. Acta Neurol Scand 110:322-330, 2004

81. Tullberg M, Jensen C, Ekholm S, Wikkels $\varnothing$ C: Normal pressure hydrocephalus: vascular white matter changes on MR images must not exclude patients from shunt surgery. AJNR Am J Neuroradiol 22:1665-1673, 2001

82. Uluğ AM, Truong TN, Filippi CG, Chun T, Lee JK, Yang C, et al: Diffusion imaging in obstructive hydrocephalus. AJNR Am J Neuroradiol 24:1171-1176, 2003

83. Walchenbach R, Geiger E, Thomeer RT, Vanneste JA: The value of temporary external lumbar CSF drainage in predicting the outcome of shunting on normal pressure hydrocephalus. J Neurol Neurosurg Psychiatry 72:503-506, 2002

84. Wikkels $\varnothing$ C, Hellström P, Klinge PM, Tans JT: The European iNPH Multicentre Study on the predictive values of resistance to CSF outflow and the CSF Tap Test in patients with idiopathic normal pressure hydrocephalus. J Neurol Neurosurg Psychiatry 84:562-568, 2013

85. Yamada S, Tsuchiya K, Bradley WG, Law M, Winkler ML, Borzage MT, et al: Current and emerging MR imaging techniques for the diagnosis and management of CSF flow disorders: a review of phase-contrast and time-spatial label- 
ing inversion pulse. AJNR Am J Neuroradiol 36:623-630, 2015

86. Yuan W, Mangano FT, Air EL, Holland SK, Jones BV, Altaye $\mathrm{M}$, et al: Anisotropic diffusion properties in infants with hydrocephalus: a diffusion tensor imaging study. AJNR Am J Neuroradiol 30:1792-1798, 2009

\section{Disclosures}

Dr. Keong reports that she has been supported by a Joint Royal College of Surgeons of England and Dunhill Medical Trust Fellowship, a Tunku Abdul Rahman Centenary Grant, and a National Medical Research Council Transition Award Grant, Singapore (supporting ongoing work). A Medical Research Council Programme Grant (Wolfson Brain Imaging Centre Cooperative) has supported study imaging work for the group. Dr. M. Czosnyka reports that he has been supported by grants from Johnson and Johnson-Codman, Integra, Sophysa, Aesculap (and other shunt manufacturers for work in the Cambridge Shunt Laboratory), is unpaid director of Technicam Ltd., UK, and has financial interest in the licensing fee of software ICM+ (www.neurosurg.cam. ac.uk/icmplus) used for brain monitoring, including in patients suffering from hydrocephalus. Dr. Z. Czosnyka reports that she has been supported by grants from Johnson and Johnson-Codman, Integra, Sophysa, and Aesculap (and other shunt manufacturers for work in the Cambridge Shunt Laboratory). Dr. Pickard reports that he has been supported by an NIHR Senior Investigator Award, a Medical Research Council Programme grant and an NIHR Cambridge Biomedical Research Centre grant (brain injury theme), and is a past advisor to Codman and Medtronic international advisory board, director (unpaid) of Medicam, trustee of Brain Research Trust, patron of Headway Cambridgeshire, and honorary director of National Institute for Health Research Brain Injury Healthcare Technology Cooperative. He also reports scientific collaboration with GSK (unpaid).

\section{Author Contributions}

Conception and design: Keong. Acquisition of data: Keong. Analysis and interpretation of data: all authors. Drafting the article: Keong. Critically revising the article: all authors. Reviewed submitted version of manuscript: Keong. Approved the final version of the manuscript on behalf of all authors: Keong.

\section{Correspondence}

Nicole C. H. Keong, Department of Neurosurgery, Duke-NUS Medical School, National Neuroscience Institute, 11 Jalan Tan Tock Seng, Singapore 308433, Singapore. email: nchkeong@ cantab.net. 